\title{
Crystal structure, Computational study, Optical and Vibrational properties of a new luminescent material based on bismuth(III): $\left(\mathrm{C}_{10} \mathrm{H}_{28} \mathrm{~N}_{4}\right)\left[\mathrm{Bi}_{2} \mathrm{Cl}_{10}\right]$
}

\author{
Zeineb Ouerghi ${ }^{[a]^{*}}$, Philippe Guionneau ${ }^{[b]}$, Silvia Antonia Brandan ${ }^{[c]}$, Ersin Temel ${ }^{[d]}$ \\ and Riadh Kefi [a]
}

\author{
[a] Université de Carthage, Faculté des Sciences de Bizerte, Laboratoire de Chimie des Matériaux, \\ 7021 Zarzouna, Bizerte, Tunisia \\ ${ }^{[b]}$ CNRS, Univ. Bordeaux, Bordeaux INP, ICMCB, UMR 5026, F-33600 Pessac, France \\ ${ }^{[c]}$ Cátedra de Química General, Instituto de Química Inorgánica, Facultad de Bioquímica. Química y \\ Farmacia, Universidad Nacional de Tucumán, Ayacucho 471, (4000) San Miguel de Tucumán, \\ Tucumán, Argentina \\ [d] Giresun University, Vocational School of Technical Sciences, Department of Electric and Energy, \\ TR-28049, Giresun, Turkey
}

*Corresponding author: ouerghi_zeineb@yahoo.com

\begin{abstract}
Development of new Bi-based perovskites with various structures offers considerable potential for lead-free solar cells and other optoelectronic devices as they retain the highperforming properties of halide perovskites with high power conversion efficiency and improved long-term and environmental device stability. This work addresses the study of a new chlorobismuthate(III) hybrid compound with the chemical formula $\left(\mathrm{C}_{10} \mathrm{H}_{28} \mathrm{~N}_{4}\right)\left[\mathrm{Bi}_{2} \mathrm{Cl}_{10}\right]$, prepared at room temperature by the slow evaporation method. The resulting crystals were investigated using Single Crystal X-ray diffraction, which gave an accurate crystal structure determination that allows searching the role played by intermolecular contacts in the selfassembly of the crystal structure using Hirshfeld surface analysis. The compound was additionally characterized using FTIR and Raman spectroscopies correlated by Ab-initio calculations at different levels of theory. The optical study supports the strong absorption of the compound in the visible region showing its luminescent character with emission peaks falling in the blue and near green regions. Natural bond orbital (NBO) calculations suggest a high stability of the new hybrid material attributed to energetically electronic transitions of $\left[\mathrm{Bi}_{2} \mathrm{Cl}_{10}\right]^{4-}$ anion that probably support its interesting optical properties. The shifting of stretching modes assigned to $\mathrm{N}-\mathrm{H}$ groups belonging to the piperazine ring of the compound toward lower wavenumbers confirms well the interactions observed by NBO calculations
\end{abstract}


between $\mathrm{Cl}$ atoms of the anion with these groups. The Raman bands detected below $300 \mathrm{~cm}^{-1}$ were found in perfect agreement with the characteristic of isolated $\mathrm{Bi}_{2} \mathrm{Cl}_{10}$ anion, made up of two $\left[\mathrm{BiCl}_{5}{ }^{2-}\right]$ units. The TG-DTA analysis revealed the high stability of the compound and its decomposition at $280{ }^{\circ} \mathrm{C}$. Frontier orbital studies showed the gap values of the new hybrid and its low reactivity. Probably, the inert mapped molecular electrostatic potential (MEP) surface predicted on the new material could support its high stability and low reactivity. The complete assignments for this compound in comparison with the organic and inorganic species are also presented. HF/Lanl2dz calculations in n-hexane solution have evidenced an increase in the reactivity of the hybrid and changes of positions and intensities of IR bands, attributed to $\mathrm{NH}_{3}, \mathrm{NH}$ and $\mathrm{CH}_{2}$ stretching modes, as a consequence of interactions of the anion with those groups belonging to the cation.

\section{Graphical abstract}

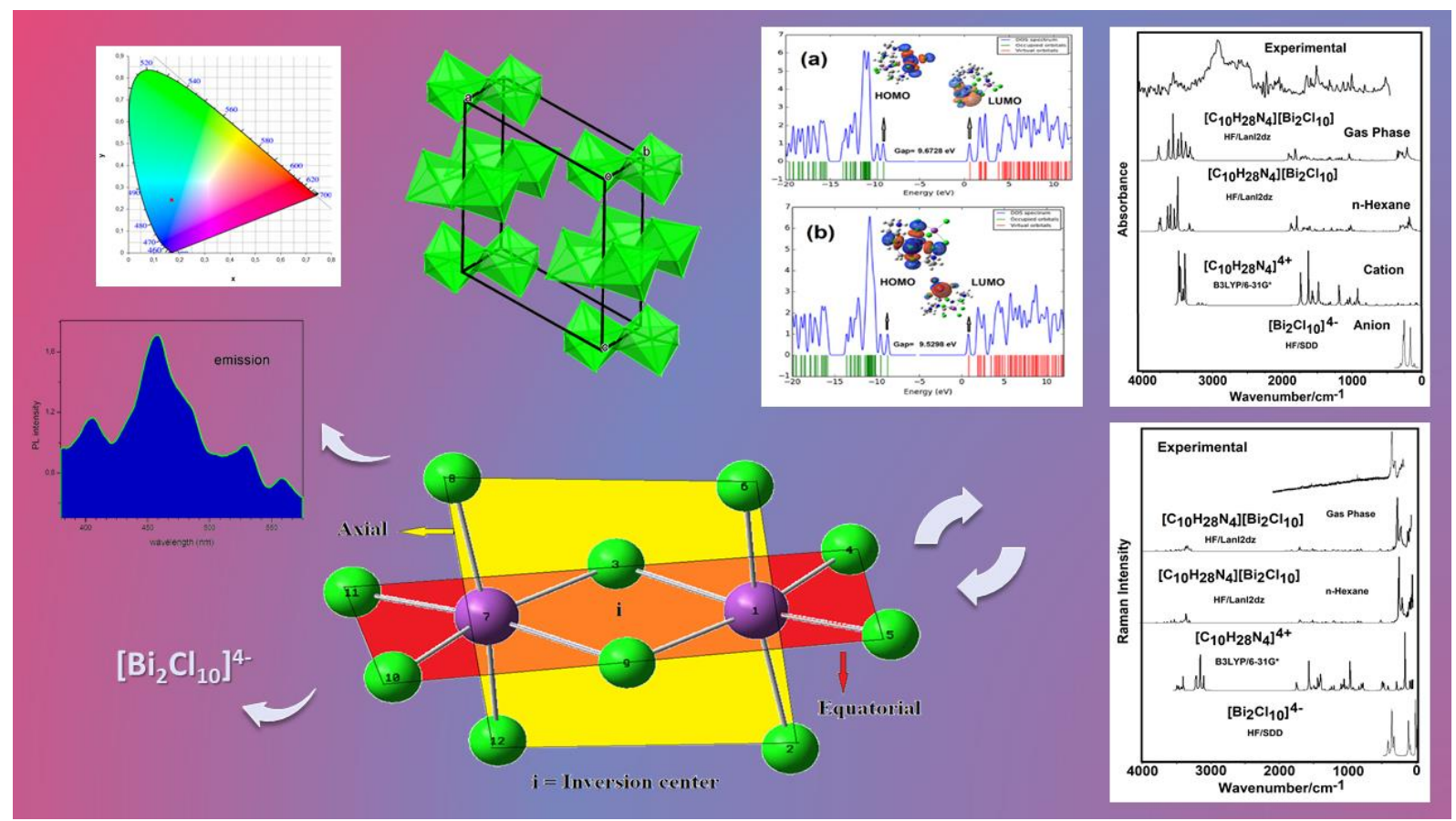

\section{Graphical abstract legend}

Synthesis and characterization of a new hybrid Bi-based compound that shows interesting photoluminescent properties were studied. Strong emission bands in the blue and near green regions were detected, related to the anionic part of the compound. Theoretical ab-initio studies using HF and DFT methods were made in the gas phase and in different solvents, to investigate the interactions that exist between organic and inorganic parts of the hybrid 
material and to examine its spectroscopic properties. Natural bond orbital (NBO), atoms in molecules (AIM), molecular electrostatic potential (MEP), and frontier orbital calculations were performed and suggest a high stability of the hybrid compound attributed to energetically electronic transitions of $\left[\mathrm{Bi}_{2} \mathrm{Cl}_{10}\right]^{4-}$ anion which probably support its interesting optical properties.

Keywords: X-Ray diffraction; Chlorobismuthate(III); FTIR; Raman spectroscopy; Photoluminescence; Hirshfeld surface analysis, Crystal structure

\section{Introduction}

Organic-inorganic hybrid materials involving trivalent metal halides have been studied intensively due to their exceptional photophysical and optical properties [1]. In fact, they associate the virtues of the two distinct classes of materials showing interesting features for optoelectronic applications and offering the possibility of having new functional species. Among these systems, several structure types have been reported to date, all of which show great promise for energy-related applications [2-4]. They are used in many fields as they integrate the functionality of inorganic species (optical, thermal, electronic properties, semiconducting behaviour, etc.) and the advantages of organic counterparts (structural flexibility and diversity, dynamic behaviour, etc.) into a single-crystal lattice through noncovalent interactions $[5,6]$. Interesting results were reported for the halogenobismuthates(III) family depending essentially on their anionic structures, symmetry and size together with their ability to form $\mathrm{H}$ bonds with the different organic amines [7-9]. From the structural point of view, $\mathrm{R}_{\mathrm{a}} \mathrm{M}_{\mathrm{b}} \mathrm{X}_{\mathrm{a}+3 \mathrm{~b}}$ derivatives ( $\mathrm{R}$ is organic cation, $\mathrm{M}=\mathrm{Bi}$ and $\mathrm{X}=\mathrm{Cl}, \mathrm{Br}, \mathrm{I}$ ) exhibit a diversity of anionic structures. These systems usually form isolated molecules zero- (0D), infinite chains one- (1D), and two- (2D) dimensional inorganic networks [10-12]. The dimensions of Bi-based halide hybrids can be controlled by selecting suitable organic cations. As demonstrated by halogenobismuthate structures, the coordination geometry of the bismuth depends on the characteristic of the halogen, the charge, size of the organic cation and the number of $\mathrm{H}$ bond donor sites of the organic part. Besides, the anionic sublattices are always built up of $\mathrm{MX}_{6}$ distorted octahedra which can be connected via corners, edges, or faces sharing [13, 14]. A characteristic feature of bismuth-based materials is their low toxicity compared to $\mathrm{Pb}^{2+}$ and $\mathrm{Sb}^{3+}$, their large availability, and low cost. Moreover, these materials 
act as potential lead-free absorber materials for solar cells [15] and present photoluminescent behaviour for which, they are used as chemical sensors, electrochemical displays, photoluminescent materials, and light-emitting diodes (LEDs), etc. [16]. These Bi-based perovskites exhibit excellent moisture stability comparing to lead-based perovskites. Due to the different valence states between lead(II) and bismuth(III), Bi-based perovskites can not be constructed simply by replacing lead(II) with bismuth(III). Therefore, cations are expected to form various vacancy-order perovskites $\mathrm{R}_{\mathrm{a}} \mathrm{Bi}_{\mathrm{b}} \mathrm{X}_{\mathrm{a}+3 \mathrm{~b}}$, according to the principle of charge conservation.

The crystal chemistry of bismuth salts is controlled by the labile distorted geometry of coordination of $\mathrm{Bi}^{3+}$ due to its stereo-active $6 \mathrm{~s}^{2}$ lone pair and by its ability for making building units made up of $\mathrm{ClBi}_{n}$ polyhedral [17]. These ions with $\mathrm{ns}^{2}$ configuration are very advantageous systems because they can exhibit extremely bright emission and also efficient excitation due to parity allowed and fast $\mathrm{s}^{2} \leftrightarrow$ sp electronic transitions. Additionally, their luminescence properties are significantly influenced by the coordination sphere of the emitting cations, which should give a degree of freedom to tune the optical properties by chemical substitution in a host-luminescent compound [18, 19]. Bismuth compounds are considered nontoxic and safe. Due to their properties, they have been widely used in medicine and their main applications are associated with ulcers, bacterial infections, and different gastrointestinal disorders [20]. The combination of bismuth complexes with the 1,4-bis(3aminopropyl)piperazine could confer to the hybrid, biological features, due to the properties, not only of the bismuth, but also of the amine [21].

In this work, we have obtained a novel organic-inorganic hybrid compound within the chlorobismuthate(III) family. We have discussed below the synthesis and the structural properties including a focus on the intermolecular interactions that govern the crystal packing. Its optical, vibrational properties and thermal behaviour are also revealed. Furthermore, we have addressed theoretical ab-initio studies by using HF and DFT methods to investigate the interactions that exist between $\left(\mathrm{C}_{10} \mathrm{H}_{28} \mathrm{~N}_{4}\right)^{4+}$ cations and $\left[\mathrm{Bi}_{2} \mathrm{Cl}_{10}\right]^{4-}$ anions into the compound together with their structural, electronic, topological and vibrational properties. In addition, the complete vibrational assignments of this hybrid chlorobismuthate derivative including the corresponding cation and anion were performed. To achieve these purposes, natural bond orbital (NBO), atoms in molecules (AIM), molecular electrostatic potential (MEP), and frontier orbital calculations were performed [22-26]. Herein, the vibrational study of these species were carried out with the SQMFF methodology and the Molvib program taking into 
account the normal internal coordinates and transferable scaling factors [27-29]. In addition to that, the scaled force constants for the cation and anion were reported. Very good concordances were obtained comparing experimental and theoretical infrared and Raman spectra, despite different methods and basis sets used in the optimization of those three species.

\section{Experimental}

\section{1 Synthesis of the compound}

The preparation of the compound consists of dissolving $(0.48 \mathrm{~g} ; 1 \mathrm{mmol})$ of $\mathrm{Bi}\left(\mathrm{NO}_{3}\right)_{3} .5 \mathrm{H}_{2} \mathrm{O}$ in a concentrated hydrochloric acid solution $(\mathrm{HCl}, 37 \%)$ and $(0.20 \mathrm{~g} ; 1$ mmol) of 1,4-bis(3-aminopropyl)piperazine in $20 \mathrm{ml}$ of water, then the mixture was stirred for 2 hours. The resulting solution evaporates giving rise to the formation of colorless crystals in a week.

The chemical reaction scheme is:

$\mathrm{C}_{10} \mathrm{H}_{24} \mathrm{~N}_{4}+2 \mathrm{Bi}\left(\mathrm{NO}_{3}\right)_{3} .5 \mathrm{H}_{2} \mathrm{O}+10 \mathrm{HCl} \longrightarrow\left(\mathrm{C}_{10} \mathrm{H}_{28} \mathrm{~N}_{4}\right)\left[\mathrm{Bi}_{2} \mathrm{Cl}_{10}\right]+6 \mathrm{HNO}_{3}+5 \mathrm{H}_{2} \mathrm{O}$

\section{2. $2 X$-ray diffraction and measurements of physical properties}

A suitable transparent crystal was picked and mounted on Bruker APEX-II with graphite monochromated $M o_{K \alpha}$ radiation $(\lambda=0.7017 \AA)$, equipped with an Oxford instruments nitrogen cryo-stream. The crystal was kept at $150 \mathrm{~K}$ during data collection. The structure was solved with SHELXS [30] using intrinsic phasing and refined using Least Squares minimization with SHELXL 2014/7 [31]. All calculations were carried out with Olex2 1.3 [32]. Crystallographic parameters and essential information of the crystalline structure of $\left(\mathrm{C}_{10} \mathrm{H}_{28} \mathrm{~N}_{4}\right)\left[\mathrm{Bi}_{2} \mathrm{Cl}_{10}\right]$ are given in Table 1. Drawings of the crystal structure were made with Ortep [33] and Mercury [34] softwares.

The IR spectrum was recorded at room temperature in the range of $4000-400 \mathrm{~cm}^{-1}$ using a NICOLET IR 200 FT-IR infrared spectrometer. The optical absorption spectrum was carried out on a Perkin Elmer Lambda $35 \mathrm{UV}-\mathrm{V}$ is spectrophotometer equipped with an integrating sphere in the range of $200-800 \mathrm{~nm}$, in the solid state, at room temperature. The emission and excitation spectra were measured with a Perkin-Elmer LS55 spectrofluorometer in the solid-state, at room temperature. The Raman spectrum was recorded between 2000 and $100 \mathrm{~cm}^{-1}$ at room temperature with a LABRAM HR800 triple monochromatic instrument using a $514.5 \mathrm{~nm}$ line spectra physics argon ion laser. The thermal spectra analysis were 
obtained with a simultaneous thermogravimetry-differential thermal analysis (TG-DTA) using "Labsys" operating from 30 up to $450^{\circ} \mathrm{C}$ temperature at an average heating rate of $5^{\circ} \mathrm{C} / \mathrm{min}$ in Argon atmosphere with a sample amount of $7.7 \mathrm{mg}$. The International Commission on Illumination (CIE) coordinates were calculated using the CIE calculator version three software.

\section{3 Hirshfeld surface analysis measurements}

Hirshfeld surface analysis offers a computationally powerful way to investigate intermolecular interactions and molecule shapes in the crystal packing. It encrypts both chemical bonding and geometry information of the molecules. The Crystal Explorer package ver. 3.1 was used to perform Hirshfeld surface calculations [35]. The CIF file of the compound was used as the input file to create the Hirshfeld surface and then the derived fingerprint plots. The normalized contact distance values $\left(\mathrm{d}_{\text {norm}}\right)$ were mapped on the Hirshfeld surface using red, blue and white colour scheme. The 2D fingerprint plots are considered unique for a molecule in a given molecular environment. They are generated by evaluating the pairs (di, de) distances from the surface to the nearest atom interior/exterior to the surface, respectively, to summarize contact distances that contribute to the Hirshfeld surface. Thus, it is possible to calculate derived properties such as the percentage of surface that involves a particular element. The surface contact data derived from the Hirshfeld surface analysis are used to derive enrichment ratios. The proportion $S_{X}$ of chemical type $X$ on the molecular surface is obtained according to the formula $S_{X}=C_{X X}+1 / 2 \sum_{y \neq x} C_{X Y}$. Enrichment ratios [36] were studied as a function of proportions of actual and random (or effective) contacts in the crystal packing depending essentially on the content of $\mathrm{H}$ and $\mathrm{Cl}$ atoms on the Hirshfeld surface. Otherwise, it provides the propensity of pairs of different chemical species participating in the formation of the crystal packing. The enrichment ratio $E_{X Y}$ is obtained by comparing the actual contacts $\mathrm{C}_{\mathrm{xy}}$ in the crystal with the theoretical proportion of random contacts $\mathrm{R}_{\mathrm{xy}}$ which is computed as if all types of contacts had the same probability to form: $E_{X Y}=C_{X Y} / R_{X Y}$. Random contacts are obtained according to the formulas: $R_{X X}=S_{X} \cdot S_{X}$ and $\mathrm{R}_{\mathrm{XY}}=2 \mathrm{~S}_{\mathrm{X}} \cdot \mathrm{S}_{\mathrm{Y}}[36]$.

\subsection{Computational details}

The GaussView program [37] was used to model the structures of the cation, the anion and the new hybrid compound while its optimizations were performed for all species in the gas phase with the Revision A.02 of Gaussian 09 program [38]. The $\left(\mathrm{C}_{10} \mathrm{H}_{28} \mathrm{~N}_{4}\right)^{4+}$ cation was optimized 
with the B3LYP/6-31G* method while for the $\left[\mathrm{Bi}_{2} \mathrm{Cl}_{10}\right]^{4-}$ anion and the compound, the HF method was used together with pseudopotentials basis sets Lanl2dz and SDD due to the presence of $\mathrm{Bi}$ atoms $[39,40]$. The compound was also optimized in water and $\mathrm{n}$-hexane solvents with the integral equation formalism variant polarised continuum method (IEFPCM) $[41,42]$ while the solvation energy was predicted by using the universal solvation model and the HF/Lanl2dz level of theory [43]. In order to detect transitions from the valence to the conduction bands, Dos spectra of the compound were compared to the experimental UVVisible spectrum. Energy levels below zero are occupied states and correspond to the valence band, while energy levels above zero energy are unoccupied states and correspond to the conduction band. Here, two solvents with different permitivities $(\varepsilon)$ values were considered in order to determine the possible solubility of the compound $\left(\varepsilon_{\text {water }}=78.3553\right.$ and $\varepsilon_{\text {n-hexane }}=$ 1.8819). The investigation of main properties were carried out at the same levels of theory and with the natural bond orbital (NBO) and atoms in molecules (AIM) 2000 programs [22-25], while the prediction on reactivities and behaviours of the species in the gas phase were performed by computing the corresponding frontier orbitals and some descriptors [26, 44-46]. In the vibrational study, the normal internal coordinates, transferable scaling factors and the corresponding harmonic force fields for the cation and the anion were computed with the scaled mechanical force field (SQMFF) methodology [27, 28]. The Molvib program was used in the scaling process to obtain the force fields and the scaled harmonic force constants [29]. The normal internal coordinates related to the cation were similar to those reported for other cations $[44,45]$ while the one corresponding to the anion were built up taking into account the $C_{i}$ symmetry and pairs of distorted $\left[\mathrm{BiCl}_{6}\right]$ octahedral, as for the hexafluorophosphate anion [46]. In the present study, potential energy distribution (PED) contributions $\geq 10 \%$ were considered in the assignments of the cation and the anion while the predicted Raman spectra for the three species were corrected from activities to intensities with recommendable equations [47, 48]. The GaussView program was used in the assignments of the new compound [37]. Thermochemical properties were predicted with the B3LYP/LanL2DZ method.

\section{Results and Discussion}

\section{1 Crystal structure}

The title compound $\left(\mathrm{C}_{10} \mathrm{H}_{28} \mathrm{~N}_{4}\right)\left[\mathrm{Bi}_{2} \mathrm{Cl}_{10}\right]$ crystallizes in the $\boldsymbol{P} 2_{1} / \boldsymbol{c}$ centrosymmetric space group of the monoclinic system. The Ortep of the structure is given in Figure 1. The 
asymmetric unit is formed by one-half of 1,4-bis(3-aminiopropyl) piperazin 1-4 dium tetra protonated cation and one-half of a decachlorobismuthate(III) dimer. The five chlorine atoms are in general positions defining a half-dimer which generates an inversion center to form $\left[\mathrm{Bi}_{2} \mathrm{Cl}_{10}\right]^{4-}$ dimer constituted of two $\left[\mathrm{BiCl}_{6}\right]^{3-}$ sharing one edge formed by two $\mathrm{Cl}^{-}$ions as it can be seen in Figure 2 (b). The projection of the atomic arrangement of the compound reveals that these isolated dimeric anions are located in the middle edges of the cell belonging to the plan $\mathrm{x}=0$ to form a (0D) network (Figure $2(\mathbf{a}, \mathbf{b})$ ). This anion architecture is similar to those found in the literature [49-52]. Anions (in green) and cations (in blue) are coloured by symmetry equivalence for the clarity of the structure arrangement (Figure 2 (b,c)). The geometry of $\mathrm{BiCl}_{6}$ octahedral chlorine coordination around the bismuth is characterized by a range of $\mathrm{Bi}-\mathrm{Cl}$ bond lengths from 2.5677(12) to 2.9214(12) $\AA$ to build a distorted octahedral $(\mathrm{ID}(\mathrm{Bi}-\mathrm{Cl})=0.83)$ [53]. There are two types of $\mathrm{Bi}-\mathrm{Cl}$ bonds: the longest one at 2.9214(12) and 2.8693(12) $\AA$ are attributed to the bond involving bridging chlorine atoms $\mathrm{Bi}-\mathrm{Cl}(5)$ and $\mathrm{Bi}-\mathrm{Cl}(5)^{\mathrm{i}}$ respectively. The shortest ones at 2.5895(11) and 2.5677(12) $\AA$ correspond to bonds involving chlorine atoms opposite to the bridging chlorine atoms ( $\mathrm{Cl} 2$ and $\mathrm{Cl}$, respectively). These $\mathrm{Bi}-\mathrm{Cl}$ distances, shortest than the sum of the Van der Waals radii of the bismuth and the chlorine atoms $3.82 \AA$, are in good conformity with data for similar compounds [54-57].

Moreover, $\mathrm{Cl}-\mathrm{Bi}-\mathrm{Cl}$ bond angles vary from $83.24(4)$ to $99.74(4)^{\circ}$ for cis, and from 168.26(4) to $172.17(4)^{\circ}$ for trans arrangements. The distortion value resultant to bond angles $(\mathrm{ID}(\mathrm{Cl}-\mathrm{Bi}-\mathrm{Cl})=0.92)[53]$ is more significant than that observed for the bonds length $(0.83)$. The distortion of the octahedral is correlated to the stereochemical activity of Bi lone pair electron [49] and deformations resulting from the $\mathrm{H}$ bond interactions [14]. The interatomic bond lengths and angles of the anion are summarised in Table 2.

The tetra protonated cation $\left(\mathrm{C}_{10} \mathrm{H}_{28} \mathrm{~N}_{4}\right)^{4+}$ occupies the empty spaces among inorganic entities. The arrangement of the organic molecules is carried out in two different orientations, up and down, as shown in Figure 2(c). The hydrogen bonds were omitted in Figure 2 for clarity and can be found in Table 3. The consistency between organic and inorganic entities is guaranteed through $\mathrm{N}-\mathrm{H} \cdots \mathrm{Cl}$ and $\mathrm{C}-\mathrm{H} \cdots \mathrm{Cl}$ hydrogen bonds, forming a three-dimensional network (see Table 3). The position of the two $\mathrm{NH}^{3+}$ groups at both ends of the organic molecule favours the three-dimensionality of the crystal packing through hydrogen bonds. The geometric parameters describing the cation geometry are recorded in Table 2. The organic entity exhibits a regular spatial configuration with normal $\mathrm{C}-\mathrm{C}, \mathrm{C}-\mathrm{N}$ distances ranging from $1.503(7)$ to $1.518(7) \AA$ and from $1.487(6)$ to $1.509(6) \AA$ respectively and $\mathrm{C}-\mathrm{C}-$ 
$\mathrm{C}, \mathrm{C}-\mathrm{C}-\mathrm{N}, \mathrm{C}-\mathrm{N}-\mathrm{C}$ angles ranging from $108.6(4)^{\circ}$ to $112.7(4)^{\circ}$. These values are compatible with those observed in the literature [58]. The conformation of the piperazinium cycle can be described in terms of Puckering coordinates, namely the evaluation of the parameters Q (total Puckering amplitude), q2, q3, $\theta$ and $\varphi$. The values for the cycle formed by N1-C1-C2-N1$\mathrm{C} 1-\mathrm{C} 2$ are equal to $\mathrm{Q}=0.4069 \AA, \mathrm{q} 2=0.4069 \AA, \mathrm{q} 3=0.000 \AA, \theta=90.00^{\circ}, \varphi=-12.23^{\circ}$ [59] and correspond well to the most stable chair conformation, of which the aminopropyl group is in the equatorial position [58].

\subsection{Hirshfeld surface Study of non-covalent interactions}

To generate our data set, the ortep of the compound was initially selected for hirshfeld calculations. The shape and environment of the molecule are characterized by the distribution of $d_{i}$ and $d_{e}$ distances in the fingerprint plots. In fact, the 3D Hirshfeld surface can be converted into a rotationally invariant two-dimensional fingerprint plots by measuring interior and exterior (di, de) distances at each point on the Hirshfeld surface and regrouping these pairs into a 2D histogram $[60,61]$. Figure 3(b) displays the semi-transparent $d_{\text {norm }}$ mapped Hirshfeld surface (HS) surrounded by all molecules that establish strong $\mathrm{H}$ bonds with it. Globally, all red spots on the $\mathrm{d}_{\text {norm-mapped }} \mathrm{HS}$ are relative to short $\mathrm{H} \cdots \mathrm{Cl} / \mathrm{Cl} \cdots \mathrm{H}$ contacts formed by these molecules, representing $\mathrm{N}-\mathrm{H} \cdots \mathrm{Cl}$ and $\mathrm{C}-\mathrm{H} \cdots \mathrm{Cl}$ hydrogen bonds in the crystal structure. They represent by far the most abundant interatomic contacts within the crystal structure since their relative contribution reaches $86 \%$ (see Figure 4). These contacts are illustrated at the top left and the bottom right of the 2D Fingerprint plots by the characteristic shape of two "wings". The $\mathrm{H} \cdots \mathrm{H}$ contacts form the second major frequent interactions in the crystal given the abundance of hydrogen on the molecular surface $\left(\mathrm{S}_{\mathrm{H}}=\right.$ $53.7 \%$ ) with an average contribution of $10.7 \%$ of the total HS (Figure 4). They are rather equally expanded over a large range of (di, de)-pairs with distances around 3.6 $\AA$. The $\mathrm{Cl} \cdots \mathrm{Cl}$ contacts exhibit relatively a sharp distribution, displaying an average of $3.3 \%$ of the HS area (Figure 4). They are generated between the anionic parts inside and outside the HS.

Table 4 summarizes the enrichment values in the compound. As expected, the $\mathrm{H} \cdots \mathrm{Cl}$ contacts show up with an enrichment ratio larger than unity $\mathrm{E}_{\mathrm{H} \cdots \mathrm{Cl}}=1.72$, making necessarily most of the surface interactions. Hence, they are the driving forces of the molecular assembly in the crystal packing. The $\mathrm{H} \cdots \mathrm{H}$ and $\mathrm{Cl} \cdots \mathrm{Cl}$ contacts show significant under-representation enrichments respectively around $\mathrm{E}_{\mathrm{H} \cdots \mathrm{H}}=0.38$ and $\mathrm{E}_{\mathrm{Cl} \cdots \mathrm{Cl}}=0.15$ indicating their low significance in the crystal cohesion. In fact, hydrogen and chlorine atoms are mainly involved in $\mathrm{H} \cdots \mathrm{Cl}$ interactions. 


\section{3 Optical properties}

The solid-state UV-vis absorption spectrum of $\left(\mathrm{C}_{10} \mathrm{H}_{28} \mathrm{~N}_{4}\right)\left[\mathrm{Bi}_{2} \mathrm{Cl}_{10}\right]$, measured at room temperature, is presented in Figure 5 (a). The title compound displays three distinct absorption bands. The first one situated at $264 \mathrm{~nm}(4.69 \mathrm{eV})$ corresponds to the highest energy, therefore, it should be rather assigned to the ligand to metal charge transfer (LMCT) transitions from $3 p\left(t_{1 g} t_{2 g} t_{1 u} t_{2 u}\right)$ orbital of $\mathrm{Cl}$ to $6 p\left(t_{1 u}\right)$ orbital of $\mathrm{Bi}($ III) [62-64]. The second intense band around $324 \mathrm{~nm}(3.82 \mathrm{eV})$, are mainly attributed to metal centred 6s6p (MC) transitions: from the $6 \mathrm{~s}^{2}\left(\mathrm{a}_{1 \mathrm{~g}}\right)$ to the $\left(\mathrm{t}_{1 \mathrm{u}}\right)$ state which correlates with the ${ }^{3} \mathrm{P}_{1}$ atomic state in $\mathrm{Bi}(\mathrm{III})$ for six coordinated $\mathrm{Bi}(\mathrm{III})$ chloro complexe $\mathrm{BiCl}_{6}$ [65]. In the $\mathrm{Bi}(\mathrm{III})$ ion, the Highest Occupied Molecular Orbital (HOMO) is predominately $6 \mathrm{~s}^{2}$ and the Lowest Unoccupied Molecular Orbital (LUMO) is predominately 6p. The third band located around $358 \mathrm{~nm}(3.46$ $\mathrm{eV}$ ) is probably attributed to metal-to-metal charge transfer (MMCT) absorptions. These transitions can be explained by the modification of the distribution of electrons between the two bismuth atoms coupled with bridging chlorine $(\mathrm{Bi}-\mathrm{Cl}-\mathrm{Bi})$. In fact, it is well known that for two metal centres that are coupled by bridging ligands can show metal-to-metal charge transfer [66-68]. The optical spectrum was recorded at a very low speed over a period time of 3 hours, which allowed us to obtain the maximum of points and, therefore, all the absorption bands appeared very clearly. This can also be seen in the graph of the gap deduced from the absorption spectrum (see Figure 5 (b)). According to the Tauc plot method, the compound presents an optical band gap of $3.1 \mathrm{eV}$, obtained by extrapolation from the linear portion of the absorption edge of $(\alpha h v)^{1 / \mathrm{n}}=A\left(h v-E_{g}\right)$, with $\mathrm{n}=1 / 2$ for direct allowed transitions, where $h$ : Planck's constant, n: the photon's frequency, $\alpha$ : the absorption coefficient, Eg: the band gap, and $A$ : a proportionality constant $[54,69]$. The band gap value is similar to other chlorobismuthates $[19,70]$.

Taking into account the good photoluminescent properties of halogenobismuthates and their potential application as photoluminescence-emitting materials, for example in chemical sensors, electrochemical displays and light-emitting diodes [71], we have examined the photoluminescent behaviour of our compound. Figure 6 shows the solid-state emission and excitation spectra of $\left(\mathrm{C}_{10} \mathrm{H}_{28} \mathrm{~N}_{4}\right)\left[\mathrm{Bi}_{2} \mathrm{Cl}_{10}\right]$ at room temperature. Under an excitation of $334 \mathrm{~nm}$, the emission spectrum features a succession of pics in the blue-green wavelength region 400$575 \mathrm{~nm}$ with a broad and intensive emission maximum located at $457 \mathrm{~nm}$. These bands are related to the mineral part, considering that saturated organic molecules show no photoluminescence bands, and therefore can not lead to the luminescence in the visible region 
(Figure 6 (a)). Consequently, the observed bands are due to electronic transitions and the recombination of excitons in the anionic part $\left[\mathrm{Bi}_{2} \mathrm{Cl}_{10}\right]^{4-}$. In the bismuth(III) chloride based hybrids, the lowest exciton state arises from excitations between the valence band, which incorporates a mixture of $\{\mathrm{Bi}(6 \mathrm{~s})+\mathrm{Cl}(3 \mathrm{p})\}$ states, and the conduction band, which derives primarily from $\mathrm{Bi}(6 \mathrm{p})$ states, and is confined zero-dimensionally in the bioctahedra $\mathrm{Bi}_{2} \mathrm{Cl}_{10}$. The CIE chromaticity coordinates of this emission are approximately $(0.171,0.241)$, which indicates the blueish emission colour of the compound slightly shifted to the green region as seen in the chromaticity diagram in Figure 7. In fact, the bismuth (III)-chloro hybrids usually exhibit long wavelength light area emission properties.

In our case, the emission and absorption spectra are the mirror image of each other. They nicely obey the mirror image symmetry rule to a large extent, as seen in Figure 6 (c). The establishment of this symmetry is considered as evidence that the molecular structure responsible for both phenomena is probably identical. When excited at $460 \mathrm{~nm}$ (Figure 6 (b)), the compound reveals two distinct emission bands at 275 and $338 \mathrm{~nm}$, well supporting the selected region of the excitation wavelength (at $334 \mathrm{~nm}$ ) previously discussed. This study, therefore, suggests the effectiveness of employing emissive hybrid $\mathrm{Bi}$ (III) based halide materials as candidates of potential blue photoluminescent materials and for solid-state lighting applications.

\section{4 Optimizations in gas phase and solution}

In Table 5 are shown calculated total energies, dipole moments and volumes of $\left(\mathrm{C}_{10} \mathrm{H}_{28} \mathrm{~N}_{4}\right)^{4+}$ cation, $\left[\mathrm{Bi}_{2} \mathrm{Cl}_{10}\right]^{4-}$ anion and $\left(\mathrm{C}_{10} \mathrm{H}_{28} \mathrm{~N}_{4}\right)\left[\mathrm{Bi}_{2} \mathrm{Cl}_{10}\right]$ compound, in the gas phase and in water and n-hexane solvents by using different theoretical methods. The $\left(\mathrm{C}_{10} \mathrm{H}_{28} \mathrm{~N}_{4}\right)^{4+}$ cation was optimized with the B3LYP/6-31G* method while the structure of $\left[\mathrm{Bi}_{2} \mathrm{Cl}_{10}\right]^{4-}$ anion was optimized with the HF method and the SDD basis set [39, 40]. The compound was also optimized with the HF method and by using two basis sets, Lanl2dz and SDD [39, 40]. The anion and cation were both optimized with $C_{i}$ symmetries while the compound with $C_{1}$ symmetry. These calculations generate inversion centers in those two species, as was also noticed in the experimental structure of the compound. A big difference in energy values was observed for the compound between both methods showing the best and most negative value with the SDD basis set. Hence, the properties of the compound were determined using the HF/SDD method. The optimized structures of the compound, the anion and the cation are shown in Figures S1, S2 and S3, respectively. Figure S1 shows the optimized structure of the new hybrid $\left(\mathrm{C}_{10} \mathrm{H}_{28} \mathrm{~N}_{4}\right)\left[\mathrm{Bi}_{2} \mathrm{Cl}_{10}\right]$ with $C_{1}$ symmetry using the HF/SDD method and some Cl-Bi 
bond lengths predicted between 3.095 and $5.797 \AA$, while Figure S2 illustrates the optimized structure of $\left[\mathrm{Bi}_{2} \mathrm{Cl}_{10}\right]^{4-}$ anion with $C_{i}$ symmetry using the HF/SDD method with axial and equatorial planes positions in different colours together with the inversion center. The structure of the anion was also optimized with $C_{i}$ symmetry through the B3LYP/6-31G* method and with the position of the inversion center located in the ring center, as shown in Figure S3. The cation and the anion show dipole moments null in the gas phase while the compound revealed a higher value with the HF/Lanl2dz (25.14 D) method, as compared with the other one $(27.15 \mathrm{D})$. The orientation and direction of the dipole moment vector for the whole compound in the gas phase, in addition to the magnitude, are illustrated in Figure S4. The vector in the compound is oriented from a $\mathrm{Cl}$ atom towards the center of the ring and with direction opposite to the anion, as observed in Figure S1. HF/Lanl2dz calculations of compound in solution have generated one imaginary frequency in water; however, in nhexane solvent positive ones are evidenced. This observation probably indicates that the compound is not soluble in water while in $n$-hexane the dipole moment value is $35.24 \mathrm{D}$. One can note that the corrected total energies by ZPVE (EZPVE) for the three species in all media present lower values than the uncorrected $(E)$ ones, as was also found in other species [44-46]. If now volumes are analyzed for the three species, we have noticed that for the compound the value is not dependent on the used method because the values are similar with both levels of theory while the anion is slightly higher than the cation, as expected due to the ten voluminous $\mathrm{Cl}$ atoms. In both solvents, the compound presents an increase in the volume being, the expansion in $n$-hexane of $3.6 \AA^{3}$. The Moldraw program was used to calculate the volume values for the three species in the gas phase [72]. The calculated volume value of the compound in the gas phase is lower $\left(4 \times 572.7=2290.8 \AA^{3}\right)$, as compared with the experimental one obtained in the solid state (for $Z=4,1286.2 \AA^{3}$ ). This is justified by the fact that calculations are carried out in the gas phase, where the packing forces were not taking into account and the molecules in the solid state are compressed into a smaller volume. For the compound in n-hexane, the solvation energy was predicted with the HF/Lanl2dz method and the integral equation formalism variant polarised continuum (IEFPCM) and universal solvation models [44-46]. Corrected solvation energy $\left(\Delta \mathrm{G}_{\mathrm{C}}\right)$ and volume variation $(\Delta \mathrm{V})$ of $\left(\mathrm{C}_{10} \mathrm{H}_{28} \mathrm{~N}_{4}\right)\left[\mathrm{Bi}_{2} \mathrm{Cl}_{10}\right]$ compound in $\mathrm{n}-\mathrm{Hexane}$ solution by using HF/Lanl2dz level of theory can be seen in Table 6. The $\Delta \mathrm{G}_{\text {(solution-Gas) }}$ value $(-249.71 \mathrm{~kJ} / \mathrm{mol})$ is obtained from Table 5 taken into account the differences $E_{\text {solvent }}-E_{\text {gas }}$ while the $-250.76 \mathrm{~kJ} / \mathrm{mol}$ value is calculated from differences $E_{Z P V E}$, hence, the values corrected by ZPVE is slightly more negative (-239.61 
$\mathrm{kJ} / \mathrm{mol}$ ) than the uncorrected ones. The $\Delta \mathrm{G}_{\mathrm{ne}}$ value corresponds to the non electrostatic terms calculated from the PCM method. In solution, the high solvation energy and dipole moment values together with the expansion volume predict a good solubility of the compound in nhexane.

Theoretically, the structure of the new hybrid is constituted by the cation and $\left[\mathrm{Bi}_{2} \mathrm{Cl}_{10}\right]^{4-}$ pairs of octahedral, where the $\mathrm{BiCl}_{6}$ octahedra sharing an edge are distorted, in similar form to $\mathrm{K}_{4}\left[\mathrm{Bi}_{2} \mathrm{Cl}_{10}\right]$ [73]. In relation to the geometrical parameters, in the anion, the predicted $\mathrm{Bi}-\mathrm{Cl}$ distances are between 2.7981 and $3.0381 \AA$ while the experimental ones are between 2.5677 and $2.9214 \AA$. In the compound, these distances change to 2.5472 and $3.2954 \AA$. Hence, the predicted values are overestimated in relation to the observed ones. Four Cl-Bi bonds were predicted between 3.095 and $5.797 \AA$ and, for these reasons, in Figure S1 they are represented by dashed lines. The $\mathrm{Cl}-\mathrm{Bi}-\mathrm{Cl}$ angles apparently are predicted underestimated in the anion between 71.95 and $168.46^{\circ}$ values, while in the compound change to 82.95 and $176.81^{\circ}$. These differences can be explained by the fact that calculations were made in the gas phase, as mentioned previously. For the cation, a better correlation was observed in bond lengths and angles because the B3LYP/6-31G* calculations generate good correlations while in the compound, despite of limited HF/SDD method employed, the C-N bonds linked to $\mathrm{NH}_{3}$ groups present values between 1.5084 and $1.5109 \AA$, very near to the observed ones. In the compound, the $\mathrm{C}-\mathrm{C}-\mathrm{N}$ angles of side chain show the same values of $108.7^{\circ}$ while the $\mathrm{C}-\mathrm{C}-\mathrm{C}$ angles of the same chain reveal values between 114.3 and $115.0^{\circ}$. The $\mathrm{C}-\mathrm{N}-\mathrm{C}$ angles of the ring vary between 110.1 and $116.2^{\circ}$, a bit different than the experimental ones. These predicted geometrical parameters show that the used HF/SDD method in the optimization of the compound generates results similar to the experimental ones and to those observed for the cation and the anion, respectively. Then, optimized structures of the new chlorobismuthate(III) hybrid compound can be used in the secure form to perform the corresponding vibrational analysis and, also, of both cationic and anionic studied species.

\section{5 Atomic charges, bond orders and Molecular electrostatic potentials}

The interesting optical properties demonstrated by the new chlorobismuthate(III) hybrid compound are mainly attributed to the electronic transitions of $\left[\mathrm{Bi}_{2} \mathrm{Cl}_{10}\right]^{4-}$ anions which could be of great interest for the design of new optical devices. Hence, the atomic Mulliken and natural population charges have been studied for cation, anion and the compound due to the changes in these parameters that could explain the reason that this new hybrid presents 
attractive properties. Table S1 shows the Mulliken and NPA charges together with bond orders, expressed as Wiberg indexes of the three species by using different theoretical methods. First, the values of both charges for the anion and the compound are compared in Figure S5 and, then, they are exhaustively analyzed. We note that charges in each moiety of the anion and the cation respectively, $\mathrm{BiCl}_{6}$ and $\mathrm{C}_{5} \mathrm{H}_{14} \mathrm{~N}_{2}$, are the same due to the $C_{i}$ symmetries but change in the compound. In the present study, the two $\mathrm{Bi}$ atoms, Bil and Bi7 belong together with the $\mathrm{Cl} 2, \mathrm{Cl}, \mathrm{Cl} 8$ and $\mathrm{Cl} 12$ atoms to the axial plane, while the $\mathrm{Cl} 3, \mathrm{Cl} 4$, $\mathrm{Cl}$, C19, Cl10 and $\mathrm{Cl} 11$ atoms to the equatorial plane, as shown in Figure S2. Figure S5 shows that NPA charges on the $\mathrm{Cl} 5$ and $\mathrm{Cl} 10$ and $\mathrm{Cl11}$ present fewer negative values in the compound while the Mulliken charges show modifications on practically all $\mathrm{Cl}$ atoms including the $\mathrm{Bi}$ atoms with exception of $\mathrm{Cl} 3, \mathrm{Cl} 4$ and $\mathrm{Cl} 6$ atoms. Thus, we have noticed that the incorporation of the cation with the anion modifies slightly the charges of the compound. If now both charges are only on $\mathrm{N}$ atoms of the cation (N7, N11, N28 and N32) and the compound (N19, N23, N40 and N44) compared in Figure S6 we observe important differences in their values. It is necessary to clarify that N11 and N32 of the cation and N23 and N40 of the compound belonging to piperazine rings have less negative charges than the other ones that belong to terminal $\mathrm{NH}_{3}$ groups. We note that both charges due to its symmetries are the same in the anion and the cation separately, but changes in the compound. Hence, the Mulliken charges on N11 and N23 in the cation and N23 and N44 of rings are exactly the same. However, the NPA charges on these atoms show a large difference. These results show that both anion and cation modify their charges in the compound due to the existence of electronegative $\mathrm{Cl}$ atoms.

If now the bond orders (BO) are compared and analyzed for the three species (Figure S7), it is observed that the BOs values of $\mathrm{Bi}$ atoms do not change, however, important changes are observed in all $\mathrm{Cl}$ atoms, specifically in $\mathrm{Cl} 5, \mathrm{Cl10}$ and $\mathrm{Cl11}$ atoms belonging to the equatorial plane. Comparison between the BOs for the $\mathrm{N}$ atoms of the cation and the compound shows that the $\mathrm{N}$ atoms corresponding to the rings only change, while the terminal ones belonging to $\mathrm{NH}_{3}$ groups present practically the same values. However, when the Wiberg bond index matrix in the $\mathrm{NAO}$ basis, only the $\mathrm{Bi}$ atoms linked to $\mathrm{Cl}$ atoms in the anion are analyzed. From Table S2 and Figure S8 we observe that Bi1 is most linked to Cl5 (0.6061) and C19 (0.4938) while the $\mathrm{Bi} 7$ to $\mathrm{Cl} 10$ (0.6018) and Cl11 (0.5278). Therefore, these analyses indicate that the incorporation of the anion containing the electronegative $\mathrm{Cl}$ atoms modifies the $\mathrm{N}-\mathrm{H}$ 
and $\mathrm{C}-\mathrm{H}$ bonds of the groups linked to the piperazine ring and the $\mathrm{Bi}-\mathrm{Cl}$ distances of the equatorial positions.

Molecular electrostatic potentials (MEP) were also analyzed for the three species in the gas phase [44-46]. We have observed strong red colours on their mapped MEP surfaces, as expected because these places are nucleophilic sites. However, for the $\left[\mathrm{Bi}_{2} \mathrm{Cl}_{10}\right]^{4-}$ anion the mapped MEP in the gas phase shows green colour on the entire surface indicating typical inert regions, as shown in Figure S9. Also, in the compound we have observed a green colour on the entire mapped surface while for the cation we have observed a strong blue colour, typical of electrophilic sites, as it was expected. These atypical colorations in the anion and the compound probably can be in part justified by the pseudopotential basis set employed for its optimizations or by the high stability of the anion and the compound.

\section{6 NBO and AIM studies}

Possible interactions between the cation and the anion of the new hybrid compound can be investigated by using the Second Order Perturbation Theory Analysis of Fock Matrix in NBO Basis with the NBO program [22]. Herein, a comparison between the main delocalization energies of the $\left[\mathrm{Bi}_{2} \mathrm{Cl}_{10}\right]^{4-}$ anion and the compound using HF/SDD calculations are presented in Table S3. In the cation, no interactions were observed, and, for this reason, they are not presented. In the anion different $L P C l \rightarrow L P^{*} B i 1$ and $L P C l \rightarrow L P * B i 7$ transitions from lone pairs of $\mathrm{Cl}$ atoms toward the two $\mathrm{Bi}$ atoms are observed with a total energy of $1885.14 \mathrm{~kJ} / \mathrm{mol}$, while in the compound $\mathrm{LPCl} \rightarrow \sigma^{*} \mathrm{Bil}-\mathrm{Cl}$ or $\mathrm{LPCl} \rightarrow \sigma^{*} \mathrm{Bi}$ - $\mathrm{Cl}$ and $\mathrm{LPCl} \rightarrow \sigma^{*} \mathrm{~N}-\mathrm{H}$ transitions of higher energy $(1629.07 \mathrm{~kJ} / \mathrm{mol})$ are observed. However, other $\mathrm{LPCl} \rightarrow \sigma^{*} \mathrm{Bil}-\mathrm{Cl}$, $L P C l \rightarrow \sigma^{*} B i 7-C l, \quad L P C l \rightarrow \sigma^{*} C-H, \quad L P C l \rightarrow \sigma^{*} N-H, \quad \sigma \mathrm{C}-\mathrm{H} \rightarrow \sigma^{*} \mathrm{~N}-\mathrm{C} \quad$ and $\quad \sigma \mathrm{C}-\mathrm{C} \rightarrow \sigma^{*} \mathrm{~N}-\mathrm{C}$ transitions of lower energies $(981.09 \mathrm{~kJ} / \mathrm{mol})$ are also observed in the compound which is not detailed here. Consequently, the total energy in the new hybrid is $2682.47 \mathrm{~kJ} / \mathrm{mol}$, which is a high value compared with that of the anion. Thus, this result could justify the high stability of the compound due to the electronic transitions of $\left[\mathrm{Bi}_{2} \mathrm{Cl}_{10}\right]^{4-}$ anion that support the interesting optical properties of the new chlorobismuthate(III) hybrid compound. Besides, interactions between the cation and the anion are strongly supported by the interaction of $\mathrm{Cl}$ atoms of the anion with the $\mathrm{N}-\mathrm{H}$ groups of the piperazine ring, which are clearly demonstrated in this study by the intense $\mathrm{LPCl} \rightarrow \sigma^{*} \mathrm{~N}-\mathrm{H}$ transitions where the $\mathrm{N}$ atoms of the ring and the terminal $\mathrm{NH}_{3}$ groups are involved (N19, N40 and N44). 
Elsewhere, Bader's theory of atoms in molecules (AIM) was also tried to study the different interactions in the whole compound, the cation and in the anion, but results were obtained only for the cation probably due to the pseudopotentials basis sets (SDD) used for the anion and the compound. Molecular graphic of $\left(\mathrm{C}_{10} \mathrm{H}_{28} \mathrm{~N}_{4}\right)^{4+}$ cation showing their bond critical points $(\mathrm{BCP})$ and the ring critical point $(\mathrm{RCP})$ corresponding to the piperazine ring, using the B3LYP/6-31G* method, are illustrated in Figure S10. The topological properties, such as electron density distribution, $\rho(r)$ in the RCP is found to be 0.0174 a.u. while the Laplacian value $\nabla^{2} \rho(r)$ is 0.1075 a.u. These values are in good agreement with the results obtained for the 4-phenylpiperazine-1-ium dihydrogen phosphate which contains the same ring [74].

\section{7 Frontier orbitals and descriptors}

In this work, the HOMO and LUMO, energy band gaps, and the chemical potential $(\mu)$, electronegativity $(\chi)$, global hardness $(\eta)$, global softness $(S)$, global electrophilicity $(\omega)$ and nucleophilicity indexes $(E)$ descriptors, have been calculated for the three species in order to predict their reactivity and behavior in the gas phase taking into account the interesting properties proved by this new hybrid. Thus, these parameters for the cation, the anion and the compound were compared in Table S4 together with the equations applied to compute the descriptors. In the same table the values for the three species were compared with those reported for the 1 Ethyl-3-methylimidazolium hexafluorophosphate ionic liquid and its cation and anion in the gas phase by using B3LYP/6-311++G** calculations. First, remembering that the high gap values calculated from the differences between both frontier orbitals indicate the low reactivity. Here, we have observed low reactivities in $\left(\mathrm{C}_{10} \mathrm{H}_{28} \mathrm{~N}_{4}\right)^{4+}$ cation, $\left[\mathrm{Bi}_{2} \mathrm{Cl}_{10}\right]^{4-}$ anion and the $\left(\mathrm{C}_{10} \mathrm{H}_{28} \mathrm{~N}_{4}\right)\left[\mathrm{Bi}_{2} \mathrm{Cl}_{10}\right]$ compound with gap values closer to those observed for $\left[\mathrm{PF}_{6}{ }^{-}\right]$ion of $\left[\mathrm{EMIM}^{+}\right]\left[\mathrm{PF}_{6}{ }^{-}\right]$ionic liquid [46]. The slightly least reactive of the three species is the cation while low reactivities predicted for the anion and the hybrid are in very good agreement with the green colours observed on its mapped MEP surfaces. Probably, the differences predicted in the global electrophilicity $(\omega)$ and nucleophilicity indexes $(E)$, explain the low reactivity of the three studied species.

The character of the molecular orbitals (MO) of the compound, in the gas phase and n-hexane solution, was studied using the density of states (DOS) (Figure S11). One can notice the similarity between the predicted DOS spectrum of the hybrid compound and the corresponding experimental UV-Visible spectrum as shown in this Figure. The main contributions are located in the valence band in the range of -15 to $-10 \mathrm{eV}$. From Figure S11 
we clearly can observe that the HOMO iso-density plots in both media are located on the moiety anion $\left[\mathrm{BiCl}_{5}\right]^{2-}$, most precisely on $\mathrm{Bi} 7$ atoms while the LUMO iso-density plots are located on the other moiety of the anion (Bil atom). The DOS spectra show two peaks of similar intensities in the presence of n-hexane, both are well localized on LUMO orbital with energy equal to $0.7874 \mathrm{eV}$ and the other one localized on HOMO orbital with $\mathrm{E}_{\text {HOMO }}=-$ $8.7424 \mathrm{eV}$. Hence, the gap value is $9.5298 \mathrm{eV}$. In the gas phase, the two peaks HOMO and LUMO have practically the same intensities where the energy $\mathrm{E}_{\mathrm{HOMO}}=-9.0573 \mathrm{eV}$ and $\mathrm{E}_{\mathrm{LUMO}}$ $=0.6155 \mathrm{eV}$ with the gap value of $9.6728 \mathrm{eV}$. These results reveal that the new hybrid is mostly reactive in the $n$-hexane rather than in the gas phase and that both orbitals of the anion play an important role in the properties of the compound in solution.

\section{8 Vibrational studies}

The vibrational properties of $\left(\mathrm{C}_{10} \mathrm{H}_{28} \mathrm{~N}_{4}\right)\left[\mathrm{Bi}_{2} \mathrm{Cl}_{10}\right]$ were studied using infrared and Raman spectra. The IR spectrum, illustrated in Figure $\mathbf{8}$ of the compound in the solid phase at room temperature, is compared with the predicted IR spectra of the compound, the anion and the cation, using different theoretical methods. Also, the IR spectrum of the compound in the $\mathrm{n}$-hexane is presented in the same figure. One can note that the higher differences in solution are observed in the higher wavenumbers region due to the higher reactivity of the new hybrid in solution and to the interactions of the anion with stretching modes of $\mathrm{NH}_{3}, \mathrm{NH}$ and $\mathrm{CH}_{2}$ groups. Figure 9 shows the experimental Raman spectrum of the compound in the 2000-100 $\mathrm{cm}^{-1}$ region compared with predicted spectra of the compound, the anion and the cation, in the gas phase and then-hexane solution, using different theoretical methods. The anion presents bands in the lower wavenumber region, and, for this reason, in Figure S12, is shown a comparison between the experimental and the predicted Raman spectra for the anion and the compound in the 400-100 $\mathrm{cm}^{-1}$ region. There is a very good correlation in the number of bands in spite of the theoretical Raman of the compound that is shifted in relation to the experimental one, probably due to the employed HF/SDD method. In the anion, it is expected 30 vibration modes while in the cation 120 and in the compound 156 vibration modes. Due to the $C_{1}$ symmetry, all the vibration modes of the compound are active in both IR and Raman spectra. Here, the vibration modes of the cation and the anion were completely assigned taking into account its normal internal coordinates and the harmonic force fields determined with the SQMM methodology and the Molvib program [27-29], while for the compound the vibration modes were assigned with the aid of GaussView program [37]. Although, each of 
the vibration modes was scaled with Rauhut and Pulay factors, as indicated in Table S5. The cation and the anion present $C_{i}$ symmetries, while the compound $C_{1}$ symmetry. In Table 7 are given observed and calculated wavenumbers and all assignments for the $\left(\mathrm{C}_{10} \mathrm{H}_{28} \mathrm{~N}_{4}\right)^{4+}$ cation, $\left[\mathrm{Bi}_{2} \mathrm{Cl}_{10}\right]^{4-}$ anion and $\left(\mathrm{C}_{10} \mathrm{H}_{28} \mathrm{~N}_{4}\right)\left[\mathrm{Bi}_{2} \mathrm{Cl}_{10}\right]$ compound in the gas phase using different theoretical methods. Below, we have presented a brief discussion of some vibration modes by regions. The vibrational modes of the cation were predicted by B3lyp/6-31G* calculations between 3500 and $30 \mathrm{~cm}^{-1}$, while for the compound the HF/SDD was used between 3500 and $25 \mathrm{~cm}^{-1}$. The vibration modes corresponding to the anion are only observed in the Raman spectrum considering that these modes are predicted by HF/SDD calculations between 230 and $32 \mathrm{~cm}^{-1}$.

\section{Assignments}

3500 - $2730 \mathrm{~cm}^{-1}$ region. In this region are observed IR characteristic bands of the 1,4-bis(3aminiopropyl) piperazin 1-4 dium cation and the compound, as reported for molecules containing the piperazine ring [74]. The two $\mathrm{NH}_{3}$ groups were assigned with $C_{3 v}$ symmetry, and for this reason, the six expected symmetric and antisymmetric stretching vibrations of these groups are assigned in this region together with the symmetric and antisymmetric stretching vibrations of the $\mathrm{CH}_{2}$ groups. The group of bands observed between 2700 and 200 $\mathrm{cm}^{-1}$ can be assigned to $\mathrm{H}$ bond interactions, as was experimentally found in the crystal packing. We note that the vibration modes of the compound are predicted to the higher frequencies compared to the cation because they were not scaled.

$1600-1000 \mathrm{~cm}^{-1}$ region. In this region are expected the symmetric and antisymmetric deformation, and rocking modes of $\mathrm{NH}_{3}$ groups, deformations, wagging and rocking of $\mathrm{CH}_{2}$ groups, rocking of $\mathrm{N}-\mathrm{H}$ groups and $\mathrm{C}-\mathrm{N}$ and $\mathrm{C}-\mathrm{C}$ stretching modes. The detailed assignments of these vibration modes are presented in Table 6. Some vibration modes of the ring are also predicted in this region and, for this reason, they are assigned accordingly. Some vibration modes corresponding to $\mathrm{N}-\mathrm{H}$ groups of the compound are observed shifted toward lower wavenumbers due to the interactions observed between $\mathrm{Cl}$ atoms of the anion with those groups corresponding to the piperazine ring, as suggested by NBO calculations.

1000-100 $\mathrm{cm}^{-1}$ region. The twisting modes of $\mathrm{NH}_{3}$ and $\mathrm{CH}_{2}$ groups of the cations and the compound are predicted in this region together with $\mathrm{C}-\mathrm{N}$ and $\mathrm{C}-\mathrm{C}$ stretching modes, deformations, and torsions of its piperazine rings. Here, the vibrational assignments for the compound are slightly shifted to the higher wavenumbers than those corresponding to the 
cation, as observed from the GaussView program. Other skeletal modes, such as the CCC, $\mathrm{CCN}$ deformations and torsions are also expected in this region.

The vibration modes associated to the anion are predicted in this region. Here, the assignments were performed by comparison on similar compounds containing the $\left[\mathrm{Bi}_{2} \mathrm{Cl}_{10}\right]$ dimer and taking into account the calculations carried out here [14, 49, 54-59]. The HF/SDD calculations for the anionic sublattice made up of isolated $\mathrm{Bi}_{2} \mathrm{Cl}_{10}$ dimers composed of two $\mathrm{BiCl}_{6}$ distorted octahedra sharing one edge predict the vibration modes between 230 and 32 $\mathrm{cm}^{-1}$. The normal internal coordinates of the anion were built up considering two equatorial and axial planes, as indicated in Figure S2. Hence, the bridging chlorine atoms $\left(\mathrm{Cl} 5, \mathrm{Cl}^{\mathrm{i}}\right)$ are shared by the two octahedra leading to a significant increase of the bond lengths including these chlorine atoms, while the terminal bonds located in the opposite of the bridging ones are shortened. Therefore, the sharp strong band detected at $276 \mathrm{~cm}^{-1}$ is assigned to the terminal $\mathrm{Bi}-\mathrm{Cl}$ stretching vibration, whereas the weak bands located at 230 and $161 \mathrm{~cm}^{-1}$ are assigned to the stretching and deformation modes of the bridging $\mathrm{Bi}-\mathrm{Cl}$ bonds. The lowest peaks appearing at 133 and $114 \mathrm{~cm}^{-1}$ are assigned respectively to the $\mathrm{Cl}-\mathrm{Bi}-\mathrm{Cl}$ deformation and $\mathrm{C}-\mathrm{C}$ torsion. These results are in perfect agreement with previous works on this type of compounds. The complete and detailed assignments for the anion are observed in Table 7.

\section{9 Force fields}

The scaled force constants of the cation and the anion were calculated from the corresponding harmonic force fields by using the B3LYP/6-31G* and HF/SDD methods, respectively, computed both with the SQMFF methodology and the Molvib program [27-29]. The main scaled force constants are exposed in Table 8. These parameters are of great interest to analyse the forces of different bonds. The cation shows that $f\left(v \mathrm{NH}_{3}\right)$ force constant values are higher than the $f(v N-H)$ force constants, as expected, this is due to the fact that the $\mathrm{NH}_{3}$ groups have three $\mathrm{N}-\mathrm{H}$ bonds and correspond to two terminal groups, while the other ones correspond only to two N-H groups of piperazine ring. This way, the interactions of $\mathrm{Cl}$ atoms with $\mathrm{N}-\mathrm{H}$ groups, predicted by NBO studies, can be justified by the low value of this force constant. On the other hand, the $f\left(v \mathrm{CH}_{2}\right)$ force constants are in good agreement with those reported for other compounds [44-46]. In relation to the force constants of the anion, the values of $f(v B i$ $\mathrm{Cl}$ ) force constants present different values probably due to the used method.

\subsection{Thermochemical analysis}


Thermochemical analysis of the new hybrid was computed at DFT/B3LYP/LanL2DZ basis set, calculated in the gas phase at $298.15 \mathrm{~K}$ and under $1 \mathrm{~atm}$ pressure. These properties are given in Table S6. Parameters such as rotation temperatures and constant, zero-point energy, thermal energy, heat capacity, entropy, enthalpy, Gibbs free energy of molecular systems were calculated with the Gaussian program. The ground states total electronic energy, which is the sum of electronic, translational, rotational and vibrational energies, was calculated as -777.57997707 Hartrees with the RB3LYP/LanL2DZ level of theory. The corrected enthalpy term related with the total energy of the system can be calculated by using the equation $H_{\text {corr. }}=E_{\text {total }}+k_{b} \times T$. In the present study, the thermal correction for enthalpy was determined as 0.421674 Hartree/particle. The zero point vibrational energy and zero point correction were computed as $264.60434 \mathrm{kcal} / \mathrm{mol}$ and 0.421674 Hartree/particle.

The corrected total electronic energy, $E_{\text {total }}+Z P E_{\text {corr. }}$, was obtained as -777.1583031 a.u. The total values for thermal energy, heat capacity and entropy were obtained as 289.696 $\mathrm{kcal} / \mathrm{mol}, 127.899 \mathrm{cal} / \mathrm{mol} \mathrm{K}$ and $256.855 \mathrm{cal} / \mathrm{mol} \mathrm{K}$, respectively. From Table $\mathbf{S 6}$ it is observed that the major contributions are due to the vibrational part with values of 287.919 $\mathrm{kcal} / \mathrm{mol}$ (for thermal energy), $121.937 \mathrm{cal} / \mathrm{mol} \mathrm{K}$ (for heat capacity), $171.850 \mathrm{cal} / \mathrm{mol} \mathrm{K}$ (for entropy). This result shows the importance of vibration analysis studies. The rotation constants used in microwave investigations were calculated as $0.09625,0.05131$ and 0.04516 $\mathrm{GHz}$ for the compound.

\section{11 Thermal analysis}

To regard the thermal stability of the compound at elevated temperature, TG-DTA measurements were conducted under argon flow from room temperature to $450{ }^{\circ} \mathrm{C}$. The thermal analysis of the crystalline powder (see Figure 10) showed that the compound lost four $\mathrm{HCl}$ molecules when the temperature reaches $280^{\circ} \mathrm{C}$, accompanied by an intense exothermic pic at $300{ }^{\circ} \mathrm{C}$ in the DTA curve. The calculated loss confirms, very well, the experimental results (observed weight loss: $15 \%$; calculated loss for $4 \mathrm{HCl}$ molecules: 14.92 $\%)$. Then, the compound undergoes a degradation of the organic part with a mass loss starting from 330 to $370{ }^{\circ} \mathrm{C}$. This phenomenon came out with two exothermic peaks in the DTA curve. At the end of the experience, we noticed the obtainment of a black deposit of carbon.

\section{12 Electronic spectrum}

The ultraviolet-visible solid-state spectrum of the compound is compared with its corresponding predicted one in the gas phase and in n-hexane solution by using Time- 
dependent DFT calculations (TD-DFT) at the HF/Lanl2dz level of theory with the Gaussian 09 program [38]. As it was mentioned above, in the experimental UV-Vis spectrum we have observed three bands at 264, 324 and $358 \mathrm{~nm}$ attributed to the ligand to metal charge transfer (LMCT) transitions and to metal-to-metal charge transfer (MMCT) absorptions, however, the two shoulders observed between 200 and $250 \mathrm{~nm}$ was not mentioned. Here, very intense bands at $190 \mathrm{~nm}$ in the gas phase and at $200 \mathrm{~nm}$ in the spectrum in solution were observed together with a weak band at $227.5 \mathrm{~nm}$ in both predicted spectra. These latter bands are clearly assigned to the $n \rightarrow \sigma^{*}$ transitions predicted for the compound by using NBO calculations (see Table S3). The other bands observed in the solid state probably were not observed in the predicted spectra because the packing forces were not considered in calculations.

\section{Conclusions}

This paper reports the synthesis of a new bismuth-based material and its physicochemical characterization. The asymmetric unit of $\left(\mathrm{C}_{10} \mathrm{H}_{28} \mathrm{~N}_{4}\right)\left[\mathrm{Bi}_{2} \mathrm{Cl}_{10}\right]$ is constituted by a half of a dimeric decachlorodibismuthate(III) tetra-anions which has the geometry of two octahedra sharing one edge, and half of 1,4-bis(3-aminiopropyl) piperazin 1-4 dium cation. The atomic arrangement can be described as tetra protonated cations $\left(\mathrm{C}_{10} \mathrm{H}_{28} \mathrm{~N}_{4}\right)^{4+}$ occupying the empty spaces among anions. Hydrogen bonds connect organic and inorganic components forming a three-dimensional network, as confirmed by atomic Mulliken and NPA charges and NBO calculations. The intermolecular interactions in the crystal were evidenced using 3D Hirshfeld surface, 2D fingerprint plots, and enrichment ratios which enabled the decoding of the quantitative contribution of the interactions present in the crystal system. The characteristic vibrational peaks were detected and interpreted using FTIR and Raman spectroscopy. The shifting of the stretching modes of N-H groups belonging to the compound toward lower wavenumbers confirms the interactions observed by NBO calculations between $\mathrm{Cl}$ atoms of the anion with those groups corresponding to the piperazine ring. The optical properties were investigated by UV-visible absorption and photoluminescence measurements which show strong emission bands in the blue and near green region related to the anionic part. The NBO calculations suggest a high stability of the chlorobismuthate(III) hybrid compound attributed to energetically electronic transitions of $\left[\mathrm{Bi}_{2} \mathrm{Cl}_{10}\right]^{4-}$ anion that probably support its interesting optical properties. The band gap energy was found to be $3.1 \mathrm{eV}$ determined by the Tauc model. Thermal analysis revealed that the compound remains stable up to $280^{\circ} \mathrm{C}$. Frontier orbitals studies show the high gap values of the three species and their 
low reactivity. Complete vibrational assignments were presented for the cation, the anion and the new hybrid. The calculations in n-hexane solution have evidenced an increase in the reactivity of the new hybrid and changes of positions and intensities of IR bands associated to $\mathrm{NH}_{3}, \mathrm{NH}$ and $\mathrm{CH}_{2}$ stretching modes, as a consequence of interactions of the anion with those groups belonging to the cation.

\section{Supplementary data}

Supplementary Information: Table S1-S6 and Figures S1-S13.

Crystallographic data of the structure have been deposited in the Cambridge Crystallographic data centre CCDC 1992487. These data can be obtained free of charge via www.ccdc.cam.ac.uk/data_request/cif.

\section{Acknowledgements}

This work was supported by the Tunisian National Ministry of Higher Education and Scientific Research and with grants from CIUNT Project $N^{\circ}$ 26/D608 (Consejo de Investigaciones, Universidad Nacional de Tucumán). The authors would like to thank Prof. Tom sounds for his permission to use MOLVIB. 


\section{References}

[1] M.S. Saveleva, K. Eftekhari, A. Abalymov, T.E.L. Douglas, D. Volodkin, B.V. Parakhonskiy and A.G. Skirtach. Hierarchy of Hybrid Materials-The Place of Inorganics-inOrganics in it, Their Composition and ApplicationsFront. Chem., doi.org/10.3389/fchem.2019.00179

[2] P.A. Buikin, A.Y. Rudenko, A.B. Ilyukhin, N.P. Simonenko, K.E. Yorov, and V.Y. Kotov. Bromobismuthates of 1,1'-(1,N-Alkanediyl)bis(picolines): Synthesis, Thermal Stability, Crystal Structures, and Optical Properties, Russ. J. Coord. Chem., 46 (2020) 111 118.

[3] W. Trigui, A. Oueslati, I. Chaabane, and F. Hlel. Synthesis, crystal structure, thermal analysis and dielectric properties of $\left[\left(\mathrm{C}_{4} \mathrm{H}_{9}\right)_{4} \mathrm{~N}_{3} \mathrm{Bi}_{2} \mathrm{Cl}_{9}\right.$ compound, J. Solid State Chem. 227 (2015) 10-16.

[4] D. Fredj, R. Alkarsifi, F. Pourcin, X. Liu, N.C. Boudjada, P. Pierron, A. Nourdine, M. Boujelbene, M. Fahlman, C.V. Ackermann, L. Flandin, S.B. Dkhil, O. Margeat, and J. Ackermann. New Antimony-Based Organic-Inorganic Hybrid Material as Electron Extraction Layer for Efficient and Stable Polymer Solar Cells. Appl. Mater. Interfaces, 11 (2019) 4482044828.

[5] S.K. Abdel-Aal, A.S. Abdel-Rahman, W.M. Gamal, M. Abdel-Kader, H.S. Ayoub, A.F. El-Sherif, M.F. Kandeel, S. Bozhko, E.E. Yakimov and E.B. Yakimov. Crystal structure, vibrational spectroscopy and optical properties of a one-dimensional organic-inorganic hybrid perovskite of $\left[\mathrm{NH}_{3} \mathrm{CH}_{2} \mathrm{CH}\left(\mathrm{NH}_{3}\right) \mathrm{CH}_{2}\right] \mathrm{BiCl}_{5}$, Acta Crystallogr., Sect. B: Struct. Sci., B75 (2019) 880-886.

[6] X. Liu, G. Zhang, M. Zhu, W. Chen, Q. Zou, and T. Zeng. Polarization-enhanced photoelectric performance in a molecular ferroelectric hexane-1,6-diammonium pentaiodobismuth (HDA-BiI 5 )-based solar device, RSC Adv., 10 (2020) 1198-1203.

[7] G. Bator, T. Zeegers-Huyskens, R. Jakubas, and J. Zaleski, Structure and phase transitions in guanidinium halogenobismuthates(III), J. Mol. Struct. 570 (2001) 61-74.

[8] G. Bator, R. Jakubas, and L. Sobczyk. Molecular-Ionic Halogenoantimonates and Bismuthates - a Rich Family of Crystals Showing Attractive Properties, Cryst. Eng., 538 (1999) 459-468. 
[9] A. Piecha-Bisiorek, A. Pietraszko, G. Bator, and R. Jakubas. Structural characterization and ferroelectric ordering in $\left(\mathrm{C}_{3} \mathrm{~N}_{2} \mathrm{H}_{5}\right)_{5} \mathrm{Sb}_{2} \mathrm{Br}_{11}$, J. Solid State Chem. 181(5) (2008) 11551166.

[10] A. Piecha-Bisiorek, A. Gągor, R. Jakubas, A. Ciżman, R. Janicki, and W. Medycki. Ferroelectricity in bis(ethylammonium) pentachlorobismuthate(iii): synthesis, structure, polar and spectroscopic properties, Inorg. Chem. Front., 4 (2017) 1281-1286.

[11] K. Kahouli, A. kahouli, K. Khirouni, and S. Chaabouni. Crystal structure, thermal studies, vibrational properties, atomic Hirshfeld surface, and electrical and dielectric studies of $\left[\mathrm{C}_{9} \mathrm{H}_{14} \mathrm{~N}\right]_{3} \mathrm{BiCl}_{6}$ single crystal, J. Mol. Struct., 1199 (2020) 126944 - 126955.

[12] A.J. Dennington, and M.T. Weller. Synthesis, structure and optoelectronic properties of hybrid iodobismuthate \& iodoantimonate semiconducting materials, Dalton Trans., 47 (2018) 3469-3484.

[13] S. Ben Ali, V. Ferretti, L. Del Bianco, F. Spizzo, and M. Belhouchet. Structural, vibrational, optical properties and theoretical studies of a new organic-inorganic material: Tris-acetoguanaminium hexachlorobismuthate monohydrate, J. Mol. Struct., 1199 (2020) 126986-126996.

[14] D. Fredj, C. Ben Hassen, S. Elleuch, H. Feki, N. C. Boudjada, T. Mhiri, M. Boujelbene. Structural, vibrational and optical properties of a new organic-inorganic material: $\left(\mathrm{C}_{5} \mathrm{H}_{8} \mathrm{~N}_{3}\right)_{2}\left[\mathrm{BiCl}_{5}\right]$, Mater. Res. Bull. 85 (2017) 23-29.

[15] L.C. Lee, T.N. Huq, J.L. MacManus-Driscoll, and R.L.Z. Hoye. Research Update: Bismuth-based perovskite-inspired photovoltaic materials, APL. MATERIALS 6 (2018) 084502.

[16] W-T. Chen, J-G. Huang and X-G. Yi, In Situ Preparation, Structure, Photoluminescence and Theoretical Study of an Unusual Bismuth Complex, Acta Chim. Slov. 63 (2016) 899-904.

[17] B.G. Sukhov, S.A. Mukha, I.A. Antipova, S.A. Medvedeva, L.I. Larina, N.N. Chipanina, O.N. Kazheva, G.V. Shilov, O.A. Dyachenko and B.A. Trofimova. Stereoactive lone pair of electrons on bismuth(III): tris(3-hydroxy- 2-methyl-4H-pyran-4-onato)bismuth(III), ARKIVOC 8 (2008) 139-149.

[18] J. Olchowka. PhD thesis. University of Lille 1 (2015). 
[19] S. Trabelsie, A. Samet, H. Dammak, F. Michaud, L. Santos, Y. Abid, and S. Chaabouni. Optical properties of a new luminescent hybrid material $\left[\mathrm{C}_{6} \mathrm{~N}_{2} \mathrm{H}_{5}\right]_{3} \mathrm{BiCl}_{6}$ involving a resonance energy transfer (RET), Opt. Mater. 89 (2019) 355-360.

[20] N. Liu, C. Fu, Q. Zhang, R. Zhao, Z. Sun, P. Zhang, L. Ding and K. Deng. Multifunctionalized Polyamides Prepared by Facile Ugi Reaction as Thermosensitive, Biocompatible and Antibacterial Biomaterials, ChemistrySelect 5 (2020) 2725-2734.

[21] A. Ryckebusch, R. Deprez-Poulain, M. Debreu-Fontaine, R. Vandaele, E. Mouray, P. Grellier and C. Sergheraerta, Synthesis and antimalarial evaluation of new 1,4-bis(3aminopropyl)piperazine derivatives. Bioorg. Med. Chem. Lett. 13 (2003) 3783-3787.

[22] E.D. Glendening, J.K. Badenhoop, A.D. Reed, J.E. Carpenter, F. Weinhold, NBO 3.1; Theoretical Chemistry Institute, University of Wisconsin; Madison, WI, 1996.

[23] R.F.W. Bader, Atoms in Molecules, A Quantum Theory, Oxford University Press, Oxford, 1990, ISBN: 0198558651.

[24] F. Biegler-Köning, J. Schönbohm, D. Bayles. AIM2000; A Program to Analyze and Visualize Atoms in Molecules, J. Comput. Chem. 22 (2001) 545.

[25] B.H. Besler, K.M. Merz Jr and P.A. Kollman, Atomic charges derived from semiempirical methods, J. Comp. Chem. 11 (1990) 431-439.

[26] R.G. Parr and R.G. Pearson, Absolute hardness: companion parameter to absolute electronegativity, J. Am. Chem. Soc. 105 (1983) 7512-7516.

[27] P. Pulay, G. Fogarasi, G. Pongor, J.E. Boggs, A. Vargha, Combination of theoretical ab initio and experimental information to obtain reliable harmonic force constants. Scaled quantum mechanical (QM) force fields for glyoxal, acrolein, butadiene, formaldehyde, and ethylene. J. Am. Chem. Soc. 105 (1983) 7073.

[28] G. Rauhut and P. Pulay, Transferable scaling factors for density functional derived vibrational force fields. J. Phys. Chem. 99 (1995) 3093-3099.

[29] T. Sundius, Scaling of ab-initio force fields by MOLVIB, Vib. Spectrosc. 29 (2002) 8995.

[30] G.M. Sheldrick, A short history of SHELX, Acta Cryst. A64 (2008) 112-122.

[31] G.M. Sheldrick, Crystal structure refinement with SHELXL, Acta Cryst. C71 (2015) 3-8. 
[32] O.V. Dolomanov, L.J. Bourhis, R.J. Gildea, J.A.K. Howard and H. Puschmann, OLEX2: a complete structure solution, refinement and analysis program, J. Appl. Cryst. 42 (2009) $339-341$.

[33] L.J. Farrugia, WinGX and ORTEP for Windows: an update, J. Appl. Cryst. 45 (2012) 849-854.

[34] Mercury 4.0: from visualization to analysis, design and prediction C. F. Macrae, I. Sovago, S. J. Cottrell, P. T. A. Galek, P. McCabe, E. Pidcock, M. Platings, G. P. Shields, J. S. Stevens, M. Towler and P. A. Wood, J. Appl. Cryst., 53, 226-235, 2020

[35] S.K. Wolff, D.J. Grimwood, J.J. McKinnon, M.J. Turner, D. Jayatilaka, M.A. Spackman, CrystalExplorer. University of Western Australia, Perth, 2012.

[36] C. Jelsch, K. Ejsmont and L. Huder. The enrichment ratio of atomic contacts in crystals, an indicator derived from the Hirshfeld surface analysis, IUCrJ, 1 (2014) 119-128.

[37] A.B. Nielsen, A.J. Holder, Gauss View 5.0, User's Reference, GAUSSIAN Inc., Pittsburgh, PA, 2008.

[38] J. Frisch, G. W. Trucks, H. B. Schlegel, G. E. Scuseria, et al., Gaussian 09, Revision A.02, M. Gaussian, Inc., Wallingford CT, 2009.

[39] A.D. Becke, Density-functional exchange-energy approximation with correct asymptotic behavior, Phys. Rev. A38 (1988) 3098-3100.

[40] C. Lee, W. Yang and R.G. Parr, Development of the Colle-Salvetti correlation-energy formula into a functional of the electron density. Phys. Rev. B37 (1988) 785-789.

[41] S. Miertus, E. Scrocco, J. Tomasi, Electrostatic interaction of a solute with a continuum. Chem. Phys. 55 (1981) 117-129.

[42] J. Tomasi, J. Persico, Molecular Interactions in Solution: An Overview of Methods Based on Continous Distributions of the Solvent, Chem. Rev. 94 (1994) 2027-2094.

[43] A.V. Marenich, C.J. Cramer, D.G. Truhlar, Universal solvation model based on solute electron density and a continuum model of the solvent defined by the bulk dielectric constant and atomic surface tensions, J. Phys. Chem. B113 (2009) 6378-6396.

[44] M.A. Assenine, B. Haddad, A. Paolone, S.A. Brandán, D. Villemin, M. Boumediene, M. Rahmouni and S. Bresson, Experimental and DFT studies on Structure, spectroscopic and 
thermal properties of N-Methyl-N,N,N-trioctylammonium chloride ionic liquid, J. Mol. Struct. 5(17) (2020) 129625.

[45] D. Hadji, B. Haddad, S.A. Brandán, S.K. Panja, A. Paolone, M. Drai, D. Villemin, S. Bresson, M. Rahmouni, Synthesis, NMR, Raman, thermal and nonlinear optical properties of dicationic ionic liquids from experimental and theoretical studies, J. Mol. Struct. 1220 (2020) 128713.

[46] H. Boumediene, S.A. Brandán, A.M. Amin, A. Paolone, D. Villemin, S. Bresson, Bidentate Cation-Anion Coordination in the Ionic Liquid 1-Ethyl-3-methylimidazolium hexafluorophosphate supported by vibrational spectra and NBO, AIM and SQMFF calculations, J. Mol. Struct., 1212 (2020) 128104.

[47] G. Keresztury, S. Holly, G. Besenyei, J. Varga, A.Y. Wang and J.R. Durig. Vibrational spectra of monothiocarbamates-II. IR and Raman spectra, vibrational assignment, conformational analysis and $a b$ initio calculations of $S$-methyl- $N, N$-dimethylthiocarbamate. Spectrochim. Acta, 49A (1993) 2007-2026.

[48] D. Michalska and R. Wysokinski, The prediction of Raman spectra of platinum(II) anticancer drugs by density functional theory, Chem. Phys. Lett., 403 (2005) 211-217.

[49] S. Attia, N. Chaari and S. Chaabouni, Synthesis, Crystal Structure, and Dielectric Properties of (3-Aminopropyl-imidazolium) Pentachlorobismuthate (III) $\left[\mathrm{C}_{6} \mathrm{H}_{13} \mathrm{~N}_{3}\right] \mathrm{BiCl}_{5}, J$. Clust. Sci., 26(4) (2015) 1343-1359.

[50] S. Jarraya, R. B. Hassen, A. Daoud and T. Jouini., Dimethylammonium Pentachlorobismuthate(III), Acta Cryst., C51 (1995) 2537-2538.

[51] H. Khili, N. Chaari, M. Fliyou, A. Koumina and S. Chaabouni, Synthesis, Crystal Structure and Vibrational Properties of bis (N-benzylmethylammonium) Pentachlorobismuthate (III), JAC, 8(2) (2012) 1566-1580.

[52] A. Ouasri, H. Jeghnou, A. Rhandour and P. Roussel, Structures and phases transition in hexylenediammonium pentachlorobismuthate (III) $\left[\mathrm{NH}_{3}\left(\mathrm{CH}_{2}\right)_{6} \mathrm{NH}_{3}\right] \mathrm{BiCl}_{5}$ crystal, J. Solid State Chem., 200 (2013) 22-29.

[53] R.D. Shannon, Revised effective ionic radii and systematic studies of interatomic distances in halides and chalcogenides, Acta Cryst., A32 (1976) 751-767. 
[54] Z. Ouerghi, T. Roisnel, R. Fezai and R. Kefi, Physico-chemical characterization, Hirshfeld surface analysis and opto-electric properties of a new hybrid material: Tris (2amino-5-chloropyridinium) hexachlorobismuthate(III), J. Mol. Struct. 1173 (2018) 439-447.

[55] T. Sun, F. Liang, X. Zhang, H. Tu, Z. Lin, G. Zhang and Y. Wu. Growth, structure, optical and thermal properties of three new organic-inorganic hybrid crystals: $\left(\mathrm{C}_{2} \mathrm{H}_{7} \mathrm{~N}_{4} \mathrm{~S}\right)_{3} \mathrm{BiCl}_{6} \cdot \mathrm{H}_{2} \mathrm{O},\left(\mathrm{C}_{2} \mathrm{H}_{7} \mathrm{~N}_{4} \mathrm{~S}\right)_{2} \mathrm{BiBr}_{5}$, and $\left(\mathrm{C}_{2} \mathrm{H}_{5} \mathrm{~N}_{4} \mathrm{~S}\right)_{2} \mathrm{BiI}_{5}$, Polyhedron, 127 (2017) 478488.

[56] K-B. Chu, J-L. Xie, W-J. Chen, W-X. Lu, J-L. Song and C. Zhang. A novel bismuthbased hybrid material with highly activity for fast removal of rhodamine B under dark conditions, Polyhedron, 151 (2018) 146-151.

[57] W-Y. Yin, Y-G. Weng, M. Jiang, S-K. Yu, Q-Y. Zhu and J. Dai, A Series of Tetrathiafulvalene Bismuth Chlorides: Effects of Oxidation States of Cations on Structures and Electric Properties, Inorg. Chem., 59 (2020) 5161-5169.

[58] I. Baccar, F. Issaoui, F. Zouari, M. Hussein, E. Dhahri, M.A. Valente. Magneto-structural studies of the bis (1,4-bis (3-aminopropylamine) piperazinium) chloride pentachlorocuprate (II) trihydrate, Solid State Commun., 150 (2010) 2005-2010.

[59] D. Cremer and J. A. Pople, General definition of ring puckering coordinates, J. Am. Chem, Soc., 97 (1975) 1354-1358.

[60] A.D. Martin, J. Britton, T.L. Easun, A.J. Blake, W. Lewis and M. Schröder. Hirshfeld surface investigation of structure-directing interactions within dipicolinic acid derivatives, Cryst Growth Des. 15(4) (2015) 1697-1706.

[61] Z. Ouerghi, M.A. Fersi, S. Elleuch, T. Roisnel, A. Othmani and R. Kefi. A New Anionic Structure Type Of Chlorobismuthate Salt: X-ray Characterization, DFT, Optical and Dielectric Properties of $\left(\mathrm{C}_{4} \mathrm{H}_{10} \mathrm{~N}\right)_{8}\left[\mathrm{Bi}_{2} \mathrm{Cl}_{11}\right]\left[\mathrm{BiCl}_{6}\right] \cdot 2 \mathrm{H}_{2} \mathrm{O}$. J Clust Sci. 32 (2021) 179-191.

[62] H. Ferjani, H. Boughzala and A. Driss., Synthesis, Crystal Structure, and Characterization of a New Organic-Inorganic Hybrid Material: $\left(\mathrm{H}_{3} \mathrm{AEP}\right)_{2} \cdot\left(\mathrm{BiCl}_{6}\right) \cdot 3 \mathrm{Cl} \cdot 2 \mathrm{H}_{2} \mathrm{O}$, Journal of Crystallography, 2013 (2013) 658939-658947.

[63] A. Vogler, A. Paukner and H. Kunkely, Photochemistry of coordination compounds of the main group metals, Coord. Chem. Rev., 97 (1990) 285-297. 
[64] A. Vogler and H. Nikol, Photochemistry and photophysics of coordination compounds of the main group metals, Pure Appl. Chem., 64 (1992) 1311-1317.

[65] W. Roy Mason, Electronic Absorption and MCD Spectra for $\mathrm{BiX}_{6}^{3-}, \mathrm{X}^{3}=\mathrm{Cl}^{-}, \mathrm{Br}^{-}$, and $\mathrm{I}^{-}$, in Acetonitrile Solution: Metal-Centered vs Ligand-to-Metal Charge-Transfer Assignments. Inorg. Chem. 38 (1999) 2742-2745.

[66] G. Blasse, B.C. Grabmaier. (1994) A General Introduction to Luminescent Materials. In: Luminescent Materials. Springer, Berlin, Heidelberg. https://doi.org/10.1007/978-3-64279017-1_1

[67] G. Blasse, Structure and Bonding, 76, Springer, Berlin, 1991.

[68] A. Vogler, H. Kunkely. Ligand-to-ligand and intraligand charge transfer and their relation to charge transfer interactions in organic zwitterions, Coord. Chem. Rev., 251 (2007) 577-583.

[69] Tauc, J., Optical Properties of Solids, F. Abeles (Ed.), North Holland Publishers, Amsterdam, 1970.

[70] Z. Ouerghi, H. Gornitzka, E. Temel, I. Dridi, and R. Kefi. A new non-centrosymmetric Chlorobismuthate(III) hybrid material: Crystal structure, optical properties and antibacterial study, J. Mol. Struct. 1181 (2019) 338-347.

[71] D-W. Zhang. W-T. Chen, and Y-F. Wang, Photoluminescence, semiconductive properties and theoretical calculation of a novel bismuth biimidazole compound, Luminescence 32 (2017) 201-205.

[72] P. Ugliengo, MOLDRAW Program, University of Torino, Dipartimento Chimica IFM, Torino, Italy, 1998.

[73] M. Khelifi, R. Zouari and A. Ben Salah, Redetermination of $\mathrm{K}_{4}\left[\mathrm{Bi}_{2} \mathrm{Cl}_{10}\right] \cdot 4 \mathrm{H}_{2} \mathrm{O}$, Acta Cryst. E64 (2008) i80.

[74] O. Noureddine, S. Gatfaoui, S. A. Brandan, A. Sagaama, H. Marouani, N. Issaoui, Experimental and DFT studies on the molecular structure, spectroscopic properties, and molecular docking of 4-phenylpiperazine-1-ium dihydrogen phosphate, J Mol. Struct. 1207 (2020) 127762. 
Figure captions

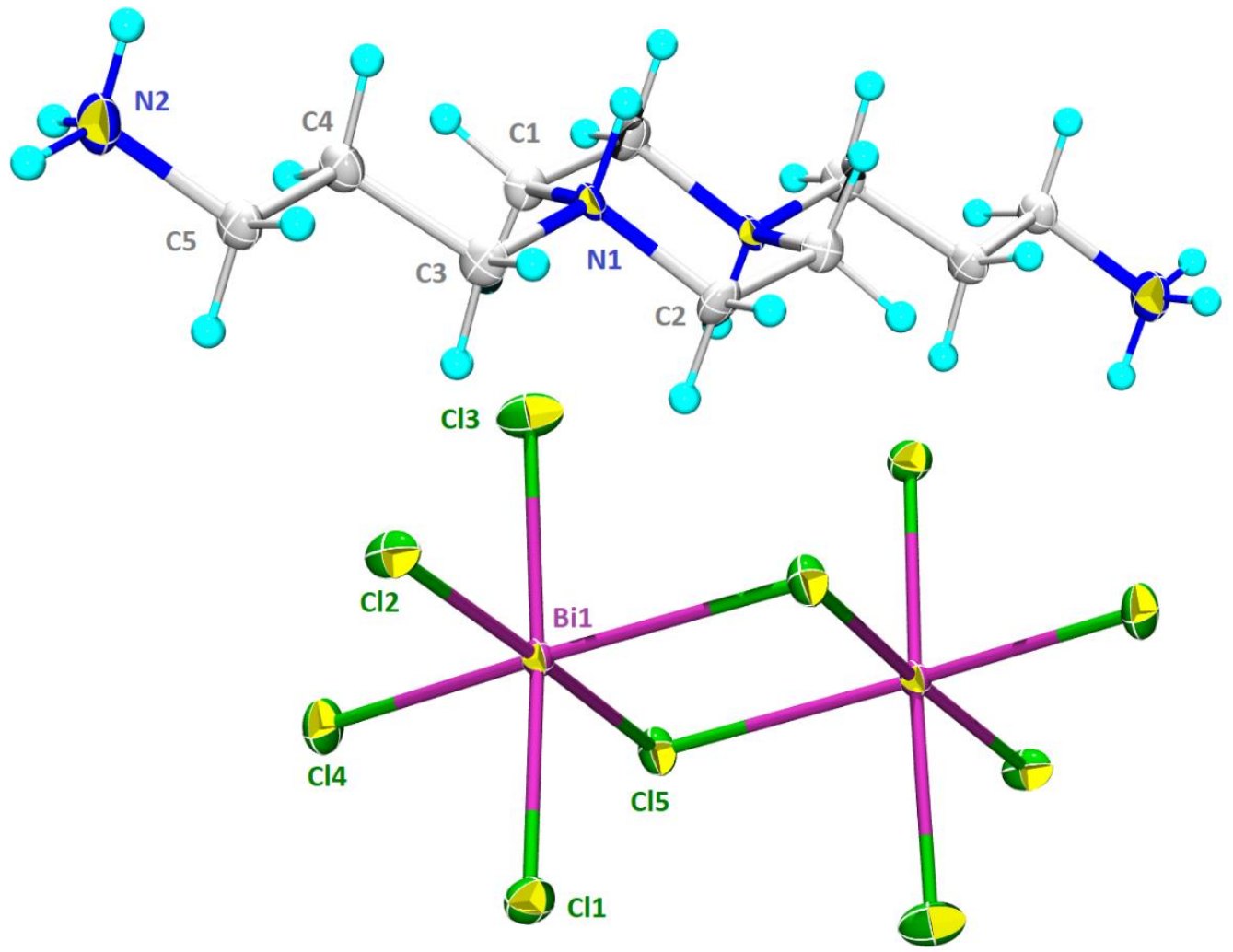

Fig 1. Ortep of the structure of $\left(\mathrm{C}_{10} \mathrm{H}_{28} \mathrm{~N}_{4}\right)\left[\mathrm{Bi}_{2} \mathrm{Cl}_{10}\right]$. The labelled part indicates the asymmetric unit of the compound. 


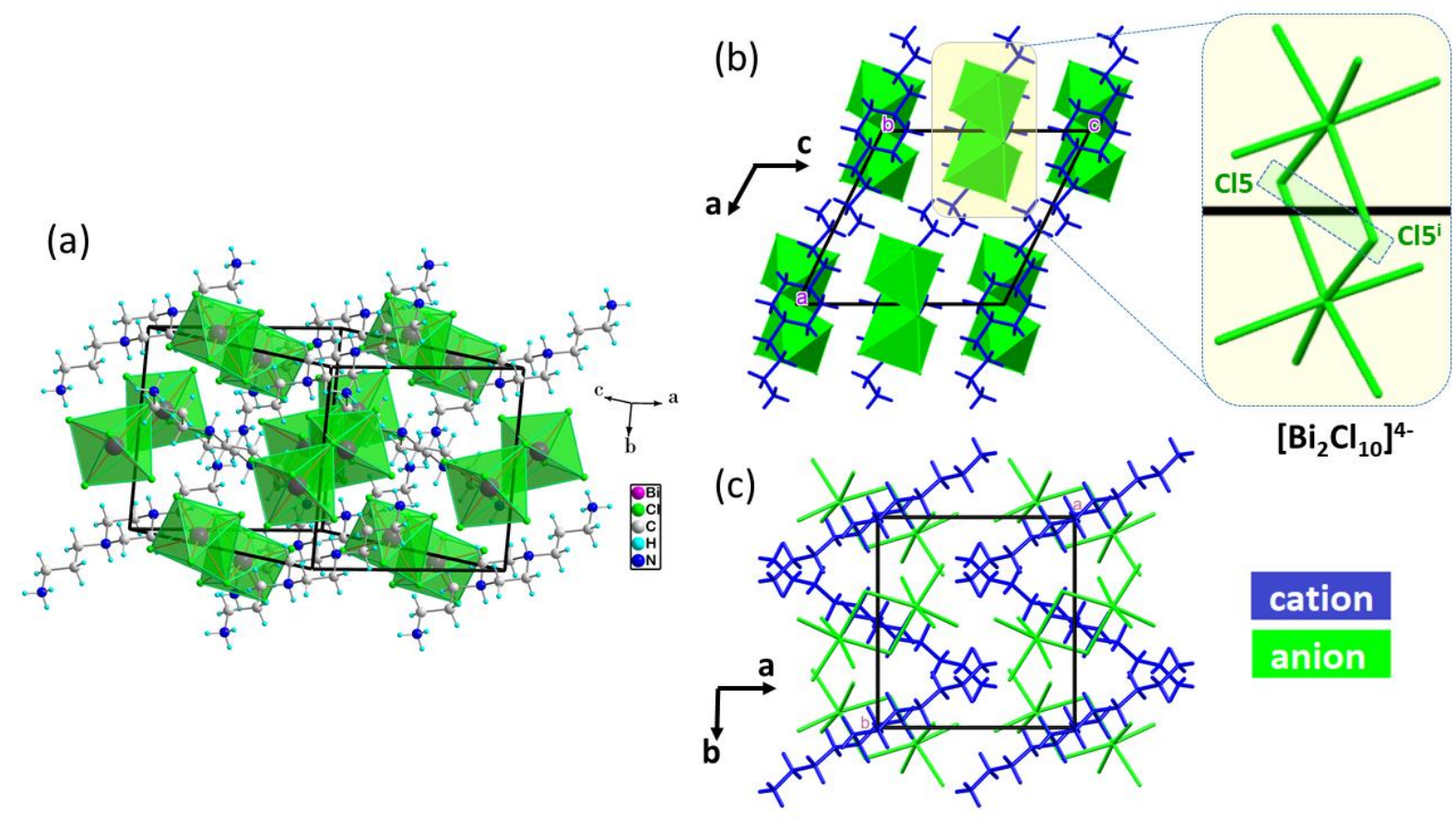

Fig 2. (a) Perspective view of $\left(\mathrm{C}_{10} \mathrm{H}_{28} \mathrm{~N}_{4}\right)\left[\mathrm{Bi}_{2} \mathrm{Cl}_{10}\right]$; (b) Geometry of $\left[\mathrm{Bi}_{2} \mathrm{Cl}_{10}\right]^{4-}$ dimer; (c) Orientation of organic molecules (in blue), which occupy the empty spaces among inorganic entities (in green). 

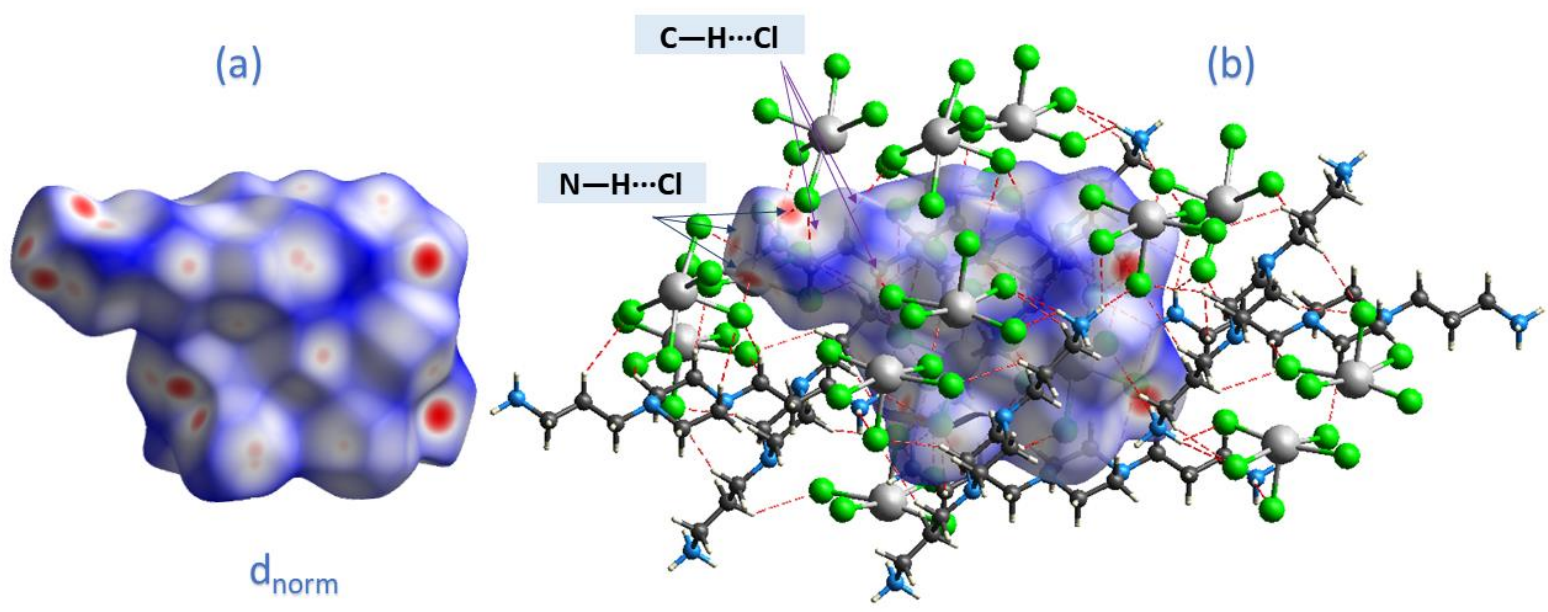

Fig. 3 (a) $d_{\text {norm }}$ mapped Hirshfeld surface (HS), (b) $d_{\text {norm }}$ shown as transparent to allow visualization of the compound surrounded by all neighbouring molecules that form strong hydrogen bonds with it. 
(a)
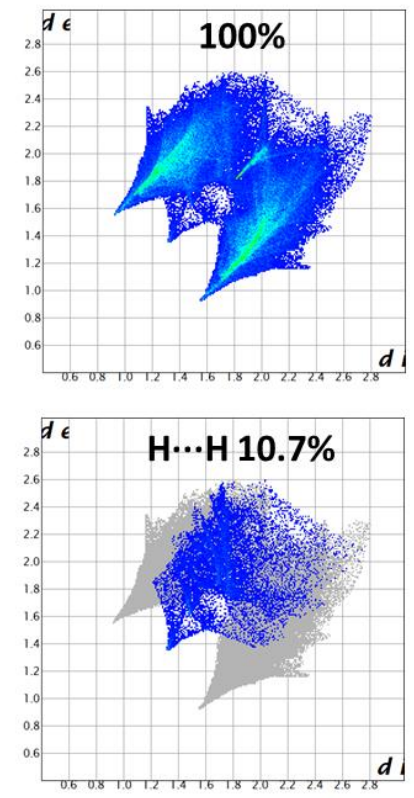
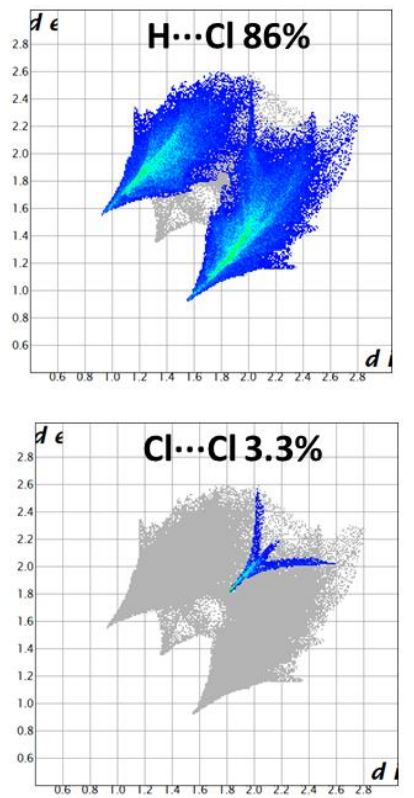

(b)

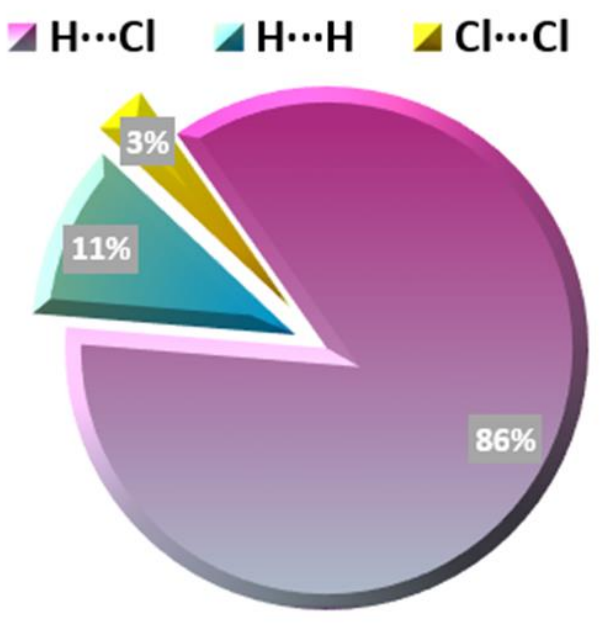

Fig. 4 (a) 2D fingerprint plots of the intermolecular contacts in the compound and (b) their relative contribution to the surface. 


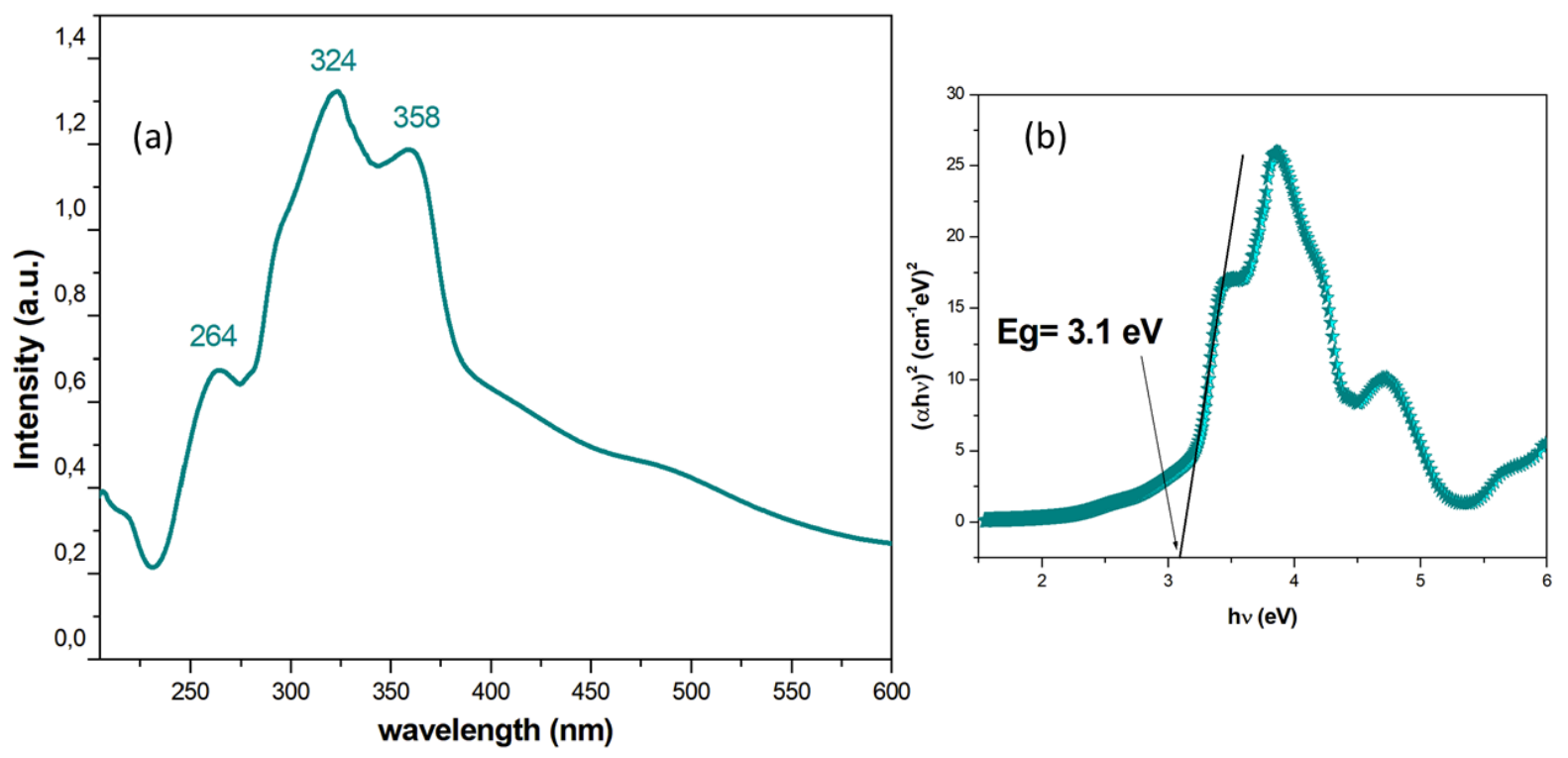

Fig. 5 (a) UV-Vis absorption spectrum of $\left(\mathrm{C}_{10} \mathrm{H}_{28} \mathrm{~N}_{4}\right)\left[\mathrm{Bi}_{2} \mathrm{Cl}_{10}\right]$, (b) energy gap deduced according to the Tauc model. 

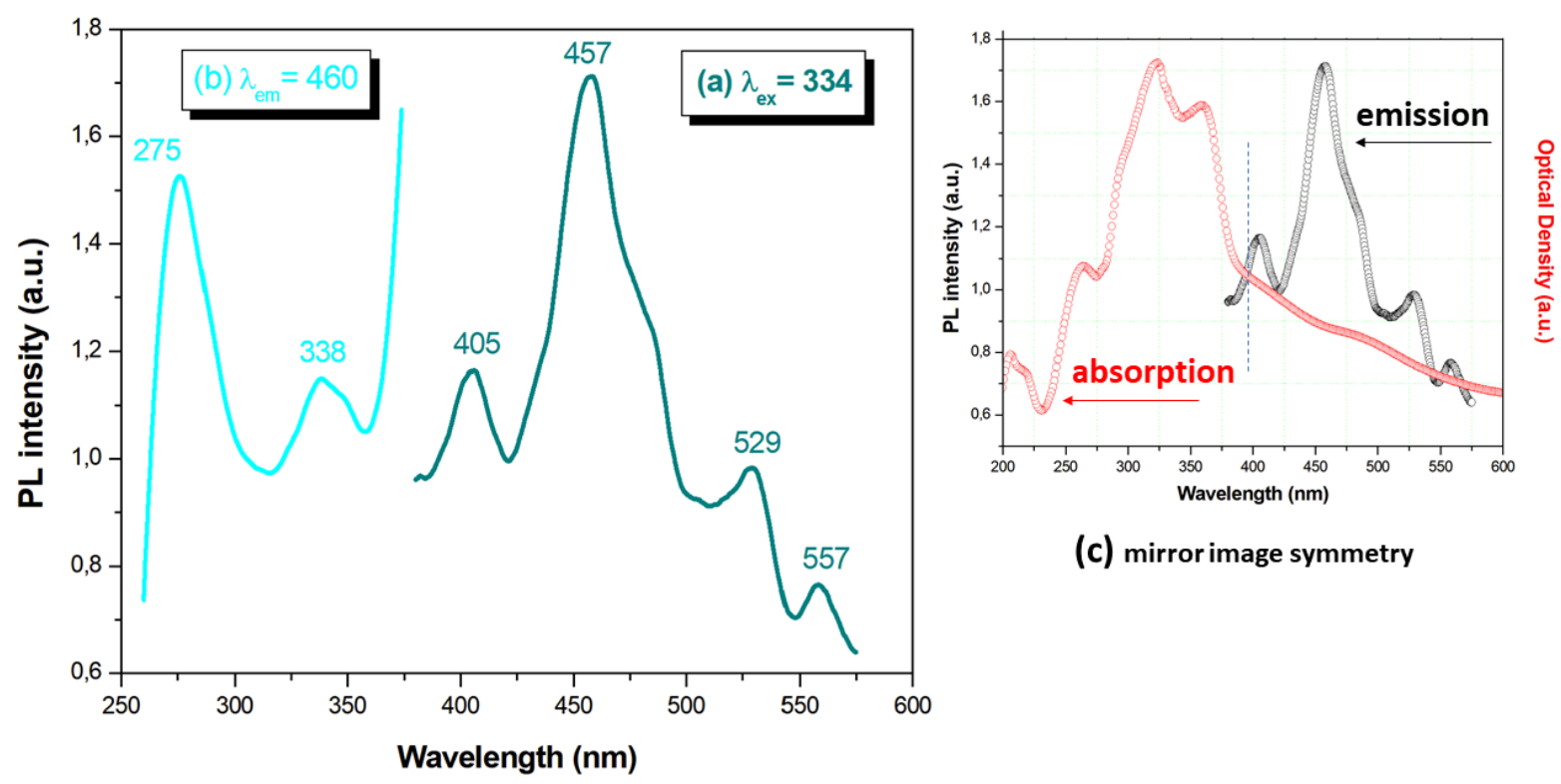

(c) mirror image symmetry

Fig. 6 Solid-state luminescence spectra: emission (a) and excitation (b) of $\left(\mathrm{C}_{10} \mathrm{H}_{28} \mathrm{~N}_{4}\right)\left[\mathrm{Bi}_{2} \mathrm{Cl}_{10}\right]$; mirror image symmetry of the emission and absorption spectra (c). 


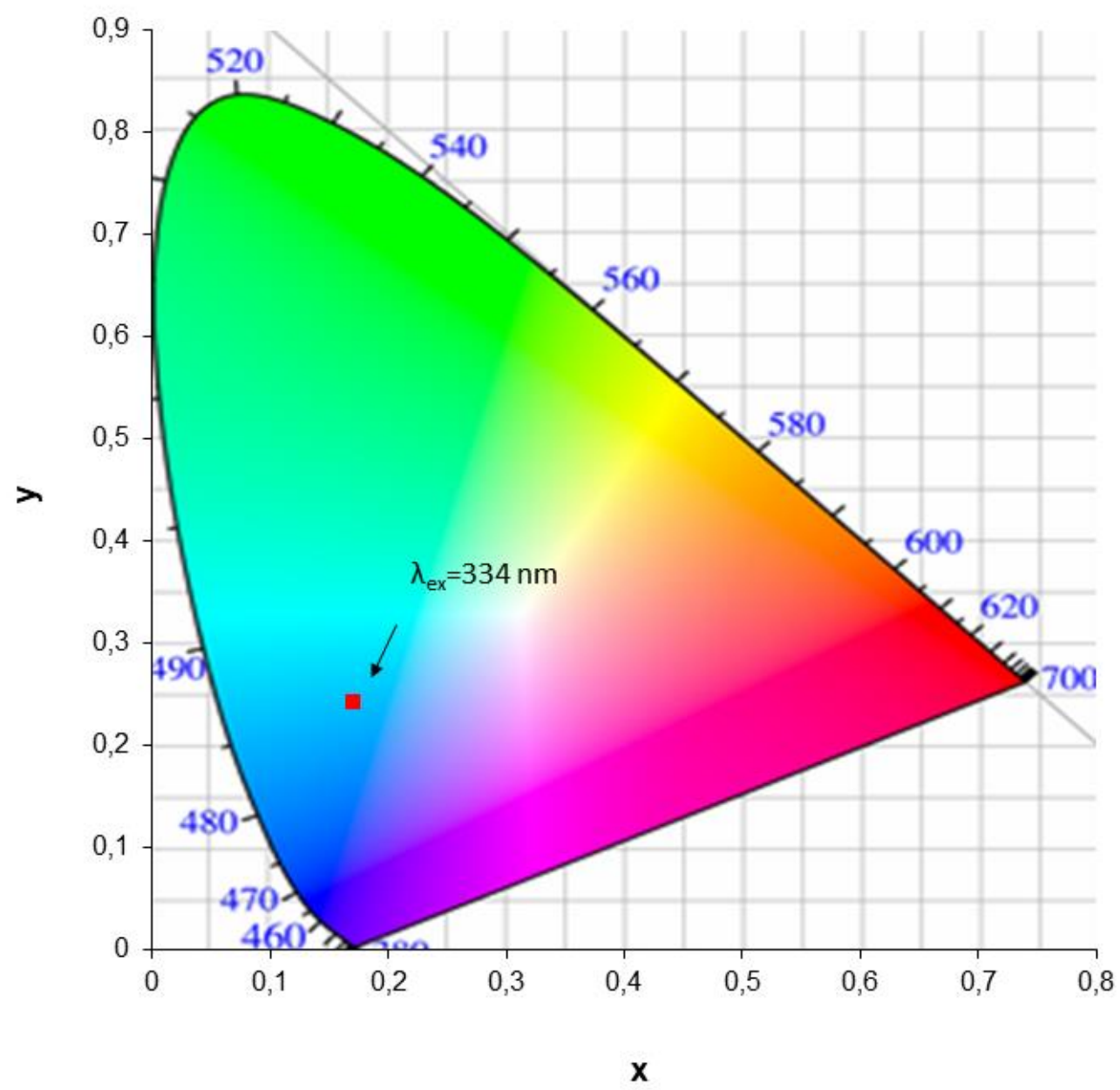

Fig. 7 CIE chromaticity diagram of the compound under an excitation of $334 \mathrm{~nm}$. 


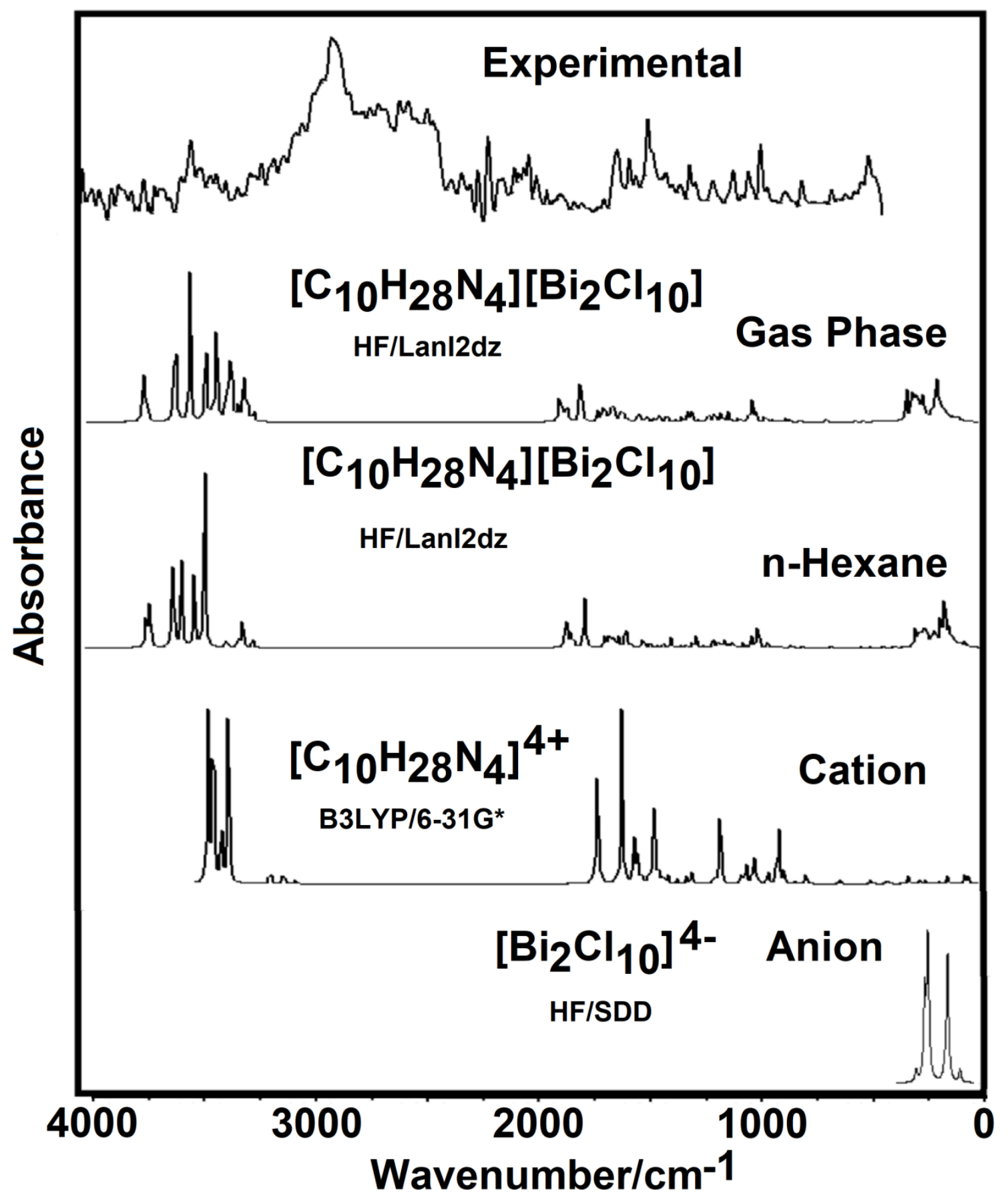

Fig.8 FTIR spectrum of $\left(\mathrm{C}_{10} \mathrm{H}_{28} \mathrm{~N}_{4}\right)\left[\mathrm{Bi}_{2} \mathrm{Cl}_{10}\right]$ in the solid phase compared with the corresponding predicted for cation, anion and compound in gas phase and n-hexane solution by using different methods. 


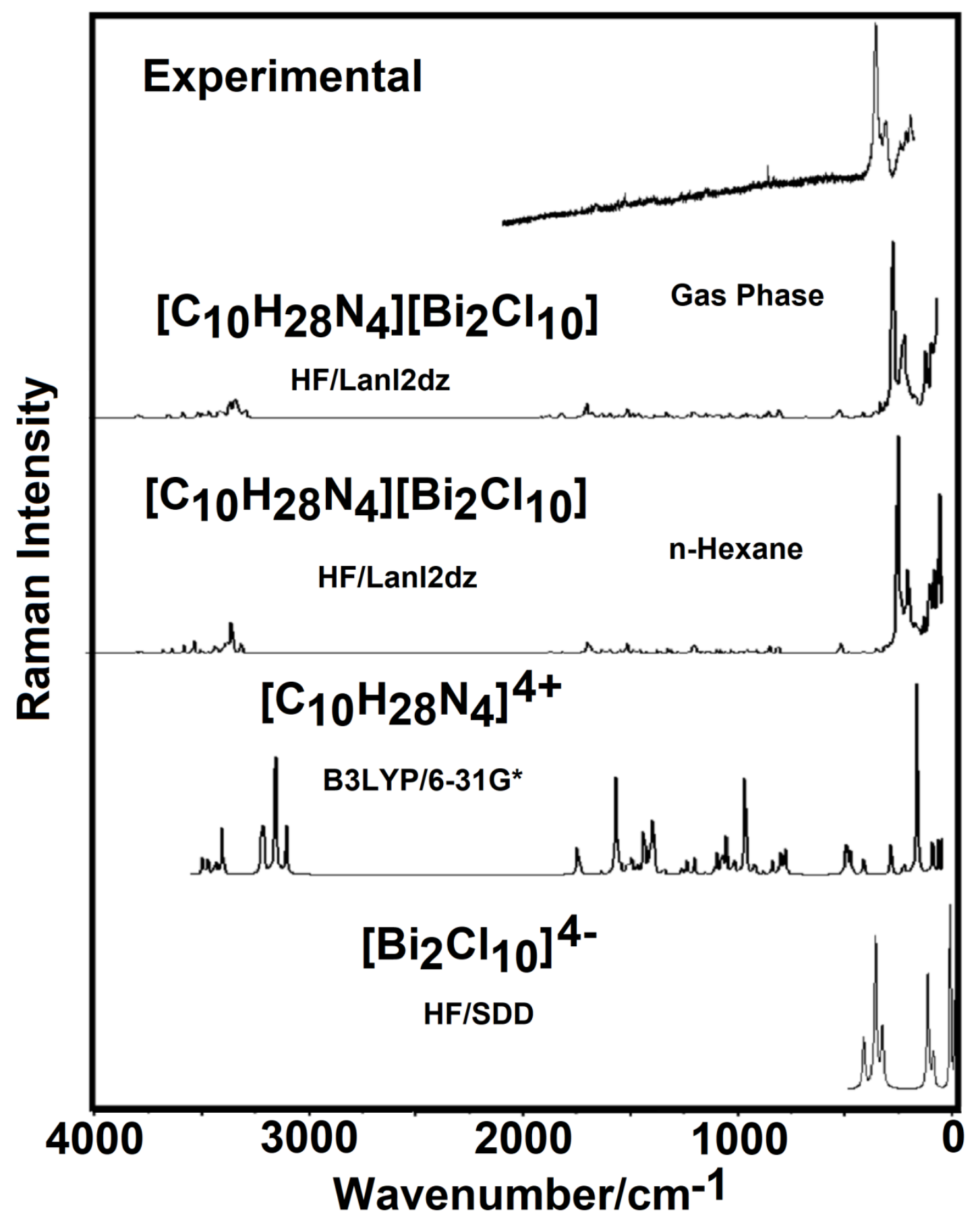

Fig. 9 Raman spectrum of $\left(\mathrm{C}_{10} \mathrm{H}_{28} \mathrm{~N}_{4}\right)\left[\mathrm{Bi}_{2} \mathrm{Cl}_{10}\right]$ recorded in the solid phase at room temperature compared with the corresponding predicted for cation, anion and compound in gas phase and n-hexane solution by using different methods. 


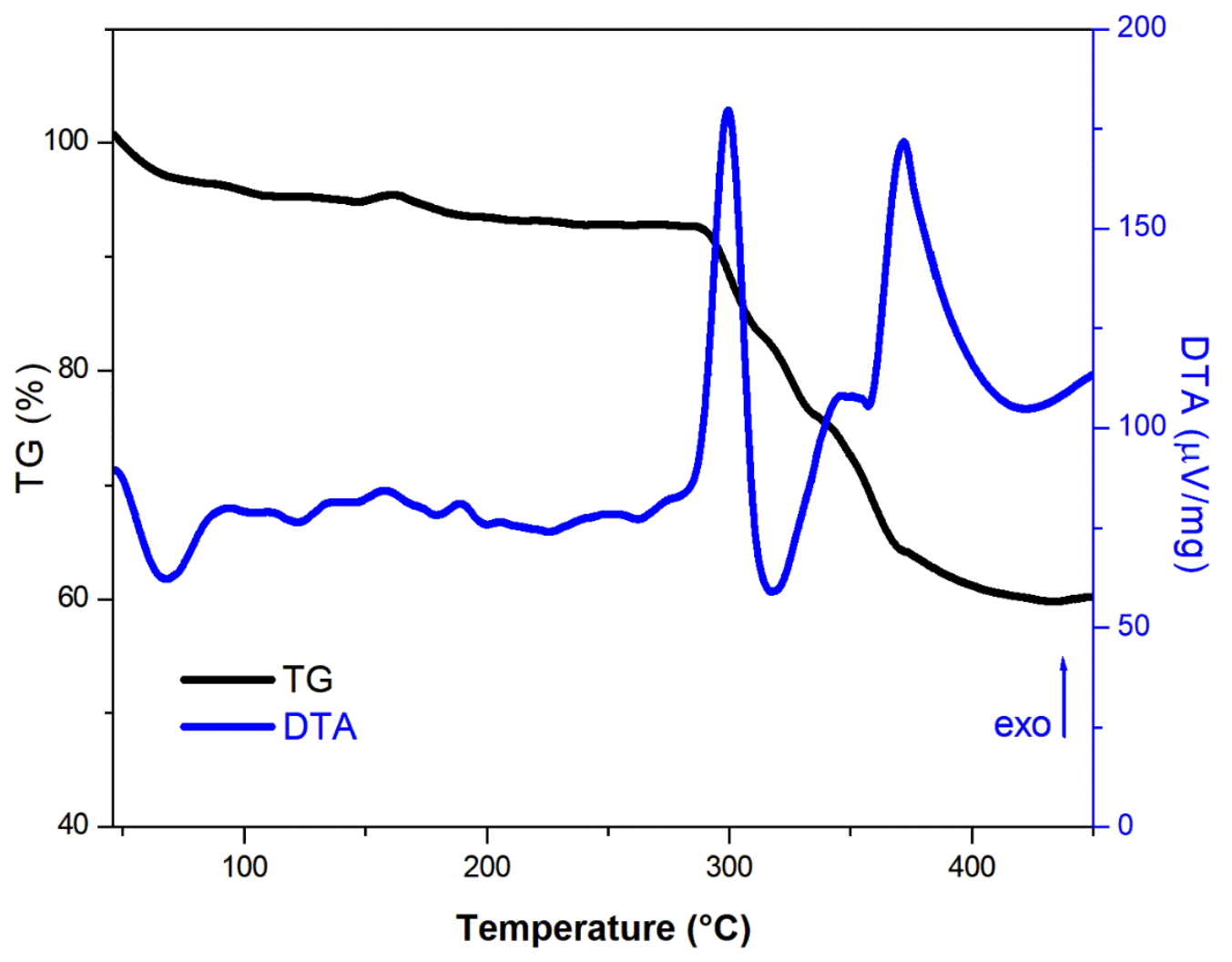

Fig. 10 TG-DTA curve of $\left(\mathrm{C}_{10} \mathrm{H}_{28} \mathrm{~N}_{4}\right)\left[\mathrm{Bi}_{2} \mathrm{Cl}_{10}\right]$. 
Table. 1 Crystallographic data and structure refinement parameters for the crystal.

\begin{tabular}{|c|c|}
\hline \multicolumn{2}{|c|}{ Crystal data } \\
\hline Chemical formula & $\left(\mathrm{C}_{10} \mathrm{H}_{28} \mathrm{~N}_{4}\right)\left[\mathrm{Bi}_{2} \mathrm{Cl}_{10}\right]$ \\
\hline$M_{\mathbf{r}}$ & 976.82 \\
\hline Crystal system, space group & $P 2_{1} / c$ \\
\hline Temperature $(\mathbf{K})$ & 150 \\
\hline$a, b, c(\AA)$ & $11.1765(10), 10.7023(10), 11.9843(11)$ \\
\hline $\boldsymbol{\beta}\left({ }^{\circ}\right)$ & $116.2052(18)$ \\
\hline$V\left(\AA^{3}\right)$ & $1286.2(2)$ \\
\hline$Z$ & 4 \\
\hline Density & 2.517 \\
\hline $\boldsymbol{\mu}\left(\mathbf{m m}^{-1}\right)$ & 14.71 \\
\hline Crystal size $\left(\mathrm{mm}^{3}\right)$ & $0.4 \times 0.2 \times 0.2$ \\
\hline \multicolumn{2}{|c|}{ Data collection } \\
\hline$T_{\min }, T_{\max }$ & $0.327,0.746$ \\
\hline $\begin{array}{l}\text { No. of measured, independent and } \\
\text { observed }[I>2 \sigma(I)] \text { reflections }\end{array}$ & $22509,3922,3655$ \\
\hline$R_{\text {int }}$ & 0.039 \\
\hline$(\Delta / \sigma)_{\max }$ & $<0.001$ \\
\hline \multicolumn{2}{|c|}{ Refinement } \\
\hline$R\left[F^{2}>2 \sigma\left(F^{2}\right)\right], w R\left(F^{2}\right), S$ & $0.029,0.068,1.07$ \\
\hline No. of reflections & 3922 \\
\hline No. of parameters & 120 \\
\hline No. of restraints & 0 \\
\hline$\Delta \rho_{\min }, \Delta \rho_{\max }\left(\mathrm{e}^{\mathrm{A}}{ }^{-3}\right)$ & $-2.87<\Delta \rho<4.23$ \\
\hline
\end{tabular}


Table. 2 Selected bond distances $(\AA)$ and angles $\left(^{\circ}\right)$ in the compound $\left(\mathrm{C}_{10} \mathrm{H}_{28} \mathrm{~N}_{4}\right)\left[\mathrm{Bi}_{2} \mathrm{Cl}_{10}\right]$.

\begin{tabular}{|c|c|c|c|}
\hline \multicolumn{4}{|c|}{ Anionic group $\left[\mathrm{Bi}_{2} \mathrm{Cl}_{10}\right]^{4-}$} \\
\hline \multicolumn{3}{|c|}{ Distances $(\AA)$} & Angles $\left(^{\circ}\right)$ \\
\hline $\mathrm{Bi} 1-\mathrm{Cl} 1$ & $2.7321(12)$ & $\mathrm{Cl1}-\mathrm{Bi} 1-\mathrm{Cl} 5$ & $99.50(4)$ \\
\hline $\mathrm{Bi} 1-\mathrm{Cl} 5 \mathrm{i}$ & $2.8693(12)$ & $\mathrm{Cl} 1-\mathrm{Bi} 1-\mathrm{Cl} 5 \mathrm{i}$ & $95.61(4)$ \\
\hline $\mathrm{Bi} 1-\mathrm{Cl} 5$ & $2.9214(12)$ & $\mathrm{Cl} 5 \mathrm{i}-\mathrm{Bi} 1-\mathrm{Cl} 5$ & $86.29(3)$ \\
\hline $\mathrm{Bi} 1-\mathrm{Cl} 4$ & $2.5677(12)$ & $\mathrm{Cl} 4-\mathrm{Bi} 1-\mathrm{Cl} 1$ & $89.15(4)$ \\
\hline $\mathrm{Bi} 1-\mathrm{Cl} 2$ & $2.5895(11)$ & $\mathrm{Cl} 4-\mathrm{Bi} 1-\mathrm{Cl} 5$ & $83.90(4)$ \\
\hline $\mathrm{Bi} 1-\mathrm{Cl} 3$ & $2.6311(12)$ & $\mathrm{Cl} 2-\mathrm{Bi} 1-\mathrm{Cl} 1$ & $84.98(4)$ \\
\hline \multirow[t]{8}{*}{$\mathrm{Cl} 5-\mathrm{Bi} 1 \mathrm{i}$} & $2.8693(12)$ & $\mathrm{Cl} 4-\mathrm{Bi} 1-\mathrm{Cl} 3$ & $93.92(4)$ \\
\hline & & $\mathrm{Cl} 2-\mathrm{Bi} 1-\mathrm{Cl} 5 \mathrm{i}$ & 99.74(4) \\
\hline & & $\mathrm{Cl} 2-\mathrm{Bi} 1-\mathrm{Cl} 5$ & $172.17(4)$ \\
\hline & & $\mathrm{Cl} 2-\mathrm{Bi} 1-\mathrm{Cl} 3$ & $83.71(4)$ \\
\hline & & $\mathrm{Cl} 3-\mathrm{Bi} 1-\mathrm{Cl} 1$ & $168.26(4)$ \\
\hline & & $\mathrm{Cl} 3-\mathrm{Bi} 1-\mathrm{Cl} 5$ & $92.09(4)$ \\
\hline & & $\mathrm{Cl} 3-\mathrm{Bi} 1-\mathrm{Cl} 5 \mathrm{i}$ & $83.24(4)$ \\
\hline & & $\mathrm{Bi} 1 \mathrm{i}-\mathrm{Cl} 5-\mathrm{Bi} 1$ & 93.71(3) \\
\hline \multicolumn{4}{|c|}{ Organic cation $\left(\mathrm{C}_{10} \mathrm{H}_{28} \mathrm{~N}_{4}\right)^{4+}$} \\
\hline \multicolumn{3}{|c|}{ Distances $(\AA)$} & Angles $\left(^{\circ}\right)$ \\
\hline $\mathrm{C} 3-\mathrm{N} 1$ & $1.509(6)$ & $\mathrm{N} 1-\mathrm{C} 3-\mathrm{C} 4$ & $112.4(4)$ \\
\hline $\mathrm{C} 4-\mathrm{C} 5$ & $1.516(7)$ & $\mathrm{C} 5-\mathrm{C} 4-\mathrm{C} 3$ & $108.6(4)$ \\
\hline $\mathrm{N} 2-\mathrm{C} 5$ & $1.487(6)$ & $\mathrm{C} 2-\mathrm{N} 1-\mathrm{C} 3$ & $109.0(3)$ \\
\hline $\mathrm{N} 1-\mathrm{C} 2$ & $1.504(6)$ & $\mathrm{C} 1-\mathrm{N} 1-\mathrm{C} 3$ & $112.7(4)$ \\
\hline $\mathrm{C} 3-\mathrm{C} 4$ & $1.518(7)$ & $\mathrm{C} 1-\mathrm{N} 1-\mathrm{C} 2$ & 109.2(3) \\
\hline $\mathrm{N} 1-\mathrm{C} 1$ & $1.504(6)$ & $\mathrm{C} 1 \mathrm{ii}-\mathrm{C} 2-\mathrm{N} 1$ & $111.9(4)$ \\
\hline $\mathrm{C} 2-\mathrm{C} 1 \mathrm{ii}$ & $1.503(7)$ & $\mathrm{C} 2 \mathrm{ii}-\mathrm{C} 1-\mathrm{N} 1$ & $110.9(4)$ \\
\hline $\mathrm{C} 1-\mathrm{C} 2 \mathrm{ii}$ & $1.503(7)$ & $\mathrm{N} 2-\mathrm{C} 5-\mathrm{C} 4$ & $109.8(4)$ \\
\hline
\end{tabular}


Table. 3 Hydrogen bonding parameters $\left(\AA{ }^{\circ}{ }^{\circ}\right)$.

\begin{tabular}{lcccc}
\hline D-H $\cdots$ A & D-H & H $\cdots$ A & D $\cdots$ A & D-H $\cdots$ A \\
\hline C4-H4B $\cdots$ Cl5 & 0.98 & 2.91 & $3.721(6)$ & 140 \\
\hline N2-H2B $\cdots$ Cl1 & 0.91 & 2.60 & $3.311(5)$ & 135 \\
\hline C1-H1B $\cdots$ Cl2iii & 0.99 & 2.79 & $3.717(5)$ & 155 \\
\hline C3-H3A $\cdots$ Cl2iii & 0.99 & 2.86 & $3.738(5)$ & 148 \\
\hline C3-H3B $\cdots$ Cl5iv & 0.99 & 2.82 & $3.764(5)$ & 158 \\
\hline N2-H2C $\cdots$ Cl2v & 0.91 & 2.53 & $3.400(4)$ & 159 \\
\hline N2-H2A $\cdots$ Cl2vi & 0.91 & 2.60 & $3.333(5)$ & 138 \\
\hline
\end{tabular}


Table. 4 Actual contacts derived random contacts, enrichment ratios and surface proportions of different species present on the molecular surface of the compound.

\begin{tabular}{|c|c|c|c|}
\hline & $\begin{array}{l}\text { Actual Contacts } \\
(C, \%)\end{array}$ & $\begin{array}{c}\text { Random Contacts } \\
(R, \%)\end{array}$ & $\begin{array}{c}\text { Enrichment } \\
(E)\end{array}$ \\
\hline $\mathrm{H} \cdots \mathrm{Cl}$ & 86 & 49.72 & 1.72 \\
\hline $\mathbf{H} \cdots \mathbf{H}$ & 10.7 & 28.83 & 0.38 \\
\hline $\mathrm{Cl} \cdots \mathrm{Cl}$ & 3.3 & 21.43 & 0.15 \\
\hline \multicolumn{4}{|c|}{ Surface proportions $(S, \%)$} \\
\hline \multicolumn{2}{|c|}{$\mathrm{S}_{\mathrm{H}}=\mathbf{5 3 . 7}$} & \multicolumn{2}{|c|}{$\mathrm{S}_{\mathrm{Cl}}=46.3$} \\
\hline
\end{tabular}


Table 5. Calculated total energies $(E)$, dipole moments $(\mu)$ and volumes $(V)$ of $\left(\mathrm{C}_{10} \mathrm{H}_{28} \mathrm{~N}_{4}\right)^{4+}$ cation, $\left[\mathrm{Bi}_{2} \mathrm{Cl}_{10}\right]^{4-}$ anion and $\left(\mathrm{C}_{10} \mathrm{H}_{28} \mathrm{~N}_{4}\right)\left[\mathrm{Bi}_{2} \mathrm{Cl}_{10}\right]$ compound in gas phase by using different theoretical methods. Corrected total energies by zero point vibrational energy (ZPVE) are also presented.

\begin{tabular}{|c|c|c|c|c|c|}
\hline \multicolumn{6}{|c|}{ Gas Phase } \\
\hline Species & Method & E (Hartrees) & $\mathrm{E}_{\mathrm{ZPVE}}$ & $\mu(\mathrm{D})$ & $\mathrm{V}\left(\AA^{3}\right)$ \\
\hline Cation & B3LYP/6-31G* & -615.4367 & -615.0237 & 0.00 & 261.5 \\
\hline Anion & HF/SDD & -4605.3571 & -4605.3491 & 0.00 & 343.7 \\
\hline Compound & $\mathrm{HF} / \mathrm{Lanl} 2 \mathrm{dz}$ & -770.6016 & -770.1422 & 27.15 & 572.5 \\
\hline Compound & $\mathrm{HF} / \mathrm{SDD}$ & -5218.0997 & -5217.6406 & 25.14 & 572.7 \\
\hline \multicolumn{6}{|c|}{$\left(\mathrm{C}_{10} \mathrm{H}_{28} \mathrm{~N}_{4}\right)\left[\mathrm{Bi}_{2} \mathrm{Cl}_{10}\right]$ in Solution } \\
\hline Medium & Method & E (Hartrees) & $\mathrm{E}_{Z \mathrm{PVE}}$ & $\mu(\mathrm{D})$ & $\mathrm{V}\left(\AA^{3}\right)$ \\
\hline Water & HF/Lanl2dz & -770.8042 & -770.3468 & 66.20 & 589.1 \\
\hline n-Hexane & HF/Lanl2dz & -770.6968 & -770.2378 & 35.24 & 576.1 \\
\hline
\end{tabular}


Table 6. Corrected solvation energy $\left(\Delta \mathrm{G}_{\mathrm{C}}\right)$ in $\mathrm{kJ} / \mathrm{mol}$ and volumes variation in $\AA^{3}(\Delta \mathrm{V})$ of $\left(\mathrm{C}_{10} \mathrm{H}_{28} \mathrm{~N}_{4}\right)\left[\mathrm{Bi}_{2} \mathrm{Cl}_{10}\right]$ compound in $\mathrm{n}-\mathrm{Hexane}$ solution by using HF/Lanl2dz level of theory.

\begin{tabular}{cccc}
\hline \multicolumn{4}{c}{ B3LYP/6-311++G** Method } \\
\hline$\Delta \mathrm{G}_{\text {(solution-Gas })}$ & $\Delta \mathrm{G}_{\mathrm{ne}}$ & $\Delta \mathrm{G}_{\mathrm{C}}$ & $\Delta \mathrm{V}\left(\AA^{3}\right)$ \\
\hline-249.71 & -11.15 & -238.56 & \\
-250.76 & -11.15 & -239.61 & 3.6 \\
\hline
\end{tabular}


Table 7. Observed and calculated wavenumbers $\left(\mathrm{cm}^{-1}\right)$ and assignments for the $\left(\mathrm{C}_{10} \mathrm{H}_{28} \mathrm{~N}_{4}\right)^{4+}$ cation, $\left[\mathrm{Bi}_{2} \mathrm{Cl}_{10}\right]^{4-}$ anion and $\left(\mathrm{C}_{10} \mathrm{H}_{28} \mathrm{~N}_{4}\right)\left[\mathrm{Bi}_{2} \mathrm{Cl}_{10}\right]$ compound in gas phase by using different theoretical methods.

\begin{tabular}{|c|c|c|c|c|c|c|c|c|c|}
\hline \multirow{2}{*}{\multicolumn{2}{|c|}{ Experimental $^{\mathrm{a}}$}} & \multirow{2}{*}{\multicolumn{3}{|c|}{$\begin{array}{l}{\left[\mathrm{Bi}_{2} \mathrm{Cl}_{10}\right]^{4-} \text { anion }{ }^{\mathrm{a}}} \\
\text { HF/SDD method }\end{array}$}} & \multicolumn{3}{|c|}{$\left(\mathrm{C}_{10} \mathrm{H}_{28} \mathrm{~N}_{4}\right)^{4+}$ cation $^{\mathrm{a}}$} & \multicolumn{2}{|c|}{$\left(\mathrm{C}_{10} \mathrm{H}_{28} \mathrm{~N}_{4}\right)\left[\mathrm{Bi}_{2} \mathrm{Cl}_{10}\right]^{\mathrm{a}}$} \\
\hline & & & & & \multicolumn{3}{|c|}{ B3LYP/6-31G* method } & \multicolumn{2}{|c|}{ HF/SDD method } \\
\hline IR & Raman & $\mathrm{SQM}^{\mathrm{b}}$ & Sym. & Assignments $^{\mathrm{a}}$ & $\mathrm{SQM}^{\mathrm{b}}$ & Sym. & Assignments $^{\mathrm{a}}$ & $\mathrm{SQM}^{\mathrm{c}}$ & Assignments $^{\mathrm{a}}$ \\
\hline $3502 \mathrm{~m}$ & & & & & 3301 & $\mathrm{Au}$ & $v_{a} \mathrm{NH}_{3}(\mathrm{~N} 28)$ & 3450 & $v_{\mathrm{a}} \mathrm{NH}_{3}$ \\
\hline $3458 w$ & & & & & 3301 & $\mathrm{Ag}$ & $v_{\mathrm{a}} \mathrm{NH}_{3}(\mathrm{~N} 7)$ & 3443 & $v_{\mathrm{a}} \mathrm{NH}_{3}$ \\
\hline $3418 w$ & & & & & 3278 & $\mathrm{Au}$ & $v_{\mathrm{a}} \mathrm{NH}_{3}(\mathrm{~N} 7)$ & 3400 & $v \mathrm{~N}-\mathrm{H}$ \\
\hline $3390 w$ & & & & & 3278 & $\mathrm{Ag}$ & $v_{\mathrm{a}} \mathrm{NH}_{3}(\mathrm{~N} 28)$ & 3285 & $v_{\mathrm{a}} \mathrm{NH}_{3}$ \\
\hline $3347 w$ & & & & & 3243 & $\mathrm{Ag}$ & $v_{\mathrm{s}} \mathrm{N}-\mathrm{H} v_{\mathrm{a}} \mathrm{N}-\mathrm{H}$ & 3200 & $v_{\mathrm{a}} \mathrm{NH}_{3}$ \\
\hline $3291 w$ & & & & & 3213 & $\mathrm{Au}$ & $v_{\mathrm{s}} \mathrm{NH}_{3}(\mathrm{~N} 28)$ & 3187 & $v_{\mathrm{a}} \mathrm{CH}_{2}$ \\
\hline $3239 w$ & & & & & 3213 & $\mathrm{Ag}$ & $v_{\mathrm{s}} \mathrm{NH}_{3}(\mathrm{~N} 7)$ & 3165 & $v_{s} \mathrm{NH}_{3}$ \\
\hline $3184 w$ & & & & & 3037 & $\mathrm{Au}$ & $v_{\mathrm{a}} \mathrm{CH}_{2}(\mathrm{C} 19)$ & 3148 & $v_{\mathrm{a}} \mathrm{CH}_{2}$ \\
\hline $3132 w$ & & & & & 3037 & $\mathrm{Ag}$ & $v_{\mathrm{a}} \mathrm{CH}_{2}(\mathrm{C} 40)$ & 3103 & $v_{\mathrm{a}} \mathrm{CH}_{2}$ \\
\hline \multirow[t]{2}{*}{$3084 w$} & & & & & 3036 & $\mathrm{Au}$ & $v_{\mathrm{a}} \mathrm{CH}_{2}(\mathrm{C} 16)$ & 3098 & $v_{\mathrm{a}} \mathrm{CH}_{2}$ \\
\hline & & & & & 3035 & $\mathrm{Au}$ & $v_{\mathrm{a}} \mathrm{CH}_{2}(\mathrm{C} 37)$ & 3088 & $v_{\mathrm{a}} \mathrm{CH}_{2}$ \\
\hline $3028 \mathrm{sh}$ & & & & & 3029 & $\mathrm{Ag}$ & $v_{\mathrm{a}} \mathrm{CH}_{2}(\mathrm{C} 22)$ & 3086 & $v_{\mathrm{a}} \mathrm{CH}_{2}$ \\
\hline \multirow[t]{3}{*}{$3028 \mathrm{sh}$} & & & & & 3029 & $\mathrm{Ag}$ & $v_{\mathrm{a}} \mathrm{CH}_{2}(\mathrm{C} 1)$ & 3079 & $v_{\mathrm{a}} \mathrm{CH}_{2}$ \\
\hline & & & & & 3027 & $\mathrm{Au}$ & $v_{\mathrm{a}} \mathrm{CH}_{2}(\mathrm{C} 13)$ & 3076 & $v_{\mathrm{S}} \mathrm{NH}_{3}$ \\
\hline & & & & & 3027 & $\mathrm{Au}$ & $v_{\mathrm{a}} \mathrm{CH}_{2}(\mathrm{C} 34)$ & 3069 & $v_{\mathrm{a}} \mathrm{CH}_{2}$ \\
\hline \multirow[t]{9}{*}{$3000 \mathrm{~m}$} & & & & & 2981 & $\mathrm{Ag}$ & $v_{\mathrm{s}} \mathrm{CH}_{2}(\mathrm{C} 40)$ & 3068 & $v_{\mathrm{a}} \mathrm{CH}_{2}$ \\
\hline & & & & & 2981 & $\mathrm{Ag}$ & $v_{s} \mathrm{CH}_{2}(\mathrm{C} 19)$ & 3064 & $v_{\mathrm{a}} \mathrm{CH}_{2}$ \\
\hline & & & & & 2978 & $\mathrm{Au}$ & $v_{\mathrm{a}} \mathrm{CH}_{2}(\mathrm{C} 25) v_{\mathrm{a}} \mathrm{CH}_{2}(\mathrm{C} 4)$ & 3051 & $v \mathrm{~N}-\mathrm{H}$ \\
\hline & & & & & 2977 & $\mathrm{Au}$ & $v_{\mathrm{a}} \mathrm{CH}_{2}(\mathrm{C} 4) v_{\mathrm{a}} \mathrm{CH}_{2}(\mathrm{C} 25)$ & 3046 & $v_{\mathrm{s}} \mathrm{CH}_{2}$ \\
\hline & & & & & 2976 & $\mathrm{Ag}$ & $v_{\mathrm{a}} \mathrm{CH}_{2}(\mathrm{C} 4) \mathrm{v}_{\mathrm{a}} \mathrm{CH}_{2}(\mathrm{C} 25)$ & 3040 & $v_{\mathrm{s}} \mathrm{CH}_{2}$ \\
\hline & & & & & 2974 & $\mathrm{Au}$ & $v_{\mathrm{s}} \mathrm{CH}_{2}(\mathrm{C} 34) v_{\mathrm{s}} \mathrm{CH}_{2}(\mathrm{Cl} 13)$ & 3027 & $v_{\mathrm{s}} \mathrm{CH}_{2}$ \\
\hline & & & & & 2974 & $\mathrm{Ag}$ & $v_{\mathrm{s}} \mathrm{CH}_{2}(\mathrm{C} 37)$ & 3026 & $v_{\mathrm{s}} \mathrm{CH}_{2}$ \\
\hline & & & & & 2971 & $\mathrm{Ag}$ & $v_{s} \mathrm{CH}_{2}(\mathrm{C} 16)$ & 3018 & $v_{\mathrm{s}} \mathrm{CH}_{2}$ \\
\hline & & & & & 2969 & $\mathrm{Au}$ & $v_{\mathrm{s}} \mathrm{CH}_{2}(\mathrm{C} 1)$ & 3011 & $v_{\mathrm{s}} \mathrm{CH}_{2}$ \\
\hline $2953 \mathrm{sh}$ & & & & & 2969 & $\mathrm{Au}$ & $v_{s} \mathrm{CH}_{2}(\mathrm{C} 22)$ & 3004 & $v_{\mathrm{s}} \mathrm{CH}_{2}$ \\
\hline $2873 \mathrm{vs}$ & & & & & 2927 & $\mathrm{Ag}$ & $v_{\mathrm{s}} \mathrm{CH}_{2}(\mathrm{C} 4)$ & 3003 & $v_{\mathrm{s}} \mathrm{CH}_{2}$ \\
\hline $2853 \mathrm{sh}$ & & & & & 2927 & $\mathrm{Au}$ & $v_{s} \mathrm{CH}_{2}(\mathrm{C} 25)$ & 3000 & $v_{\mathrm{s}} \mathrm{CH}_{2}$ \\
\hline $1648 w$ & $1630 \mathrm{vw}$ & & & & 1626 & $\mathrm{Ag}$ & $\delta_{\mathrm{a}} \mathrm{NH}_{3}(\mathrm{~N} 28)$ & 1699 & $\delta_{\mathrm{a}} \mathrm{NH}_{3}$ \\
\hline $1648 w$ & $1630 \mathrm{vw}$ & & & & 1626 & $\mathrm{Au}$ & $\delta_{\mathrm{a}} \mathrm{NH}_{3}(\mathrm{~N} 7)$ & 1693 & $\delta_{\mathrm{a}} \mathrm{NH}_{3}$ \\
\hline $1592 \mathrm{~m}$ & $1608 \mathrm{vw}$ & & & & 1618 & $\mathrm{Ag}$ & $\delta_{\mathrm{a}} \mathrm{NH}_{3}(\mathrm{~N} 7)$ & 1689 & $\delta_{\mathrm{a}} \mathrm{NH}_{3}$ \\
\hline $1592 \mathrm{~m}$ & $1608 \mathrm{vw}$ & & & & 1618 & $\mathrm{Ag}$ & $\delta_{\mathrm{a}} \mathrm{NH}_{3}(\mathrm{~N} 28)$ & 1672 & $\delta_{\mathrm{a}} \mathrm{NH}_{3}$ \\
\hline $1536 \mathrm{~m}$ & $1519 \mathrm{vw}$ & & & & 1517 & $\mathrm{Au}$ & $\delta_{\mathrm{s}} \mathrm{NH}_{3}(\mathrm{~N} 7)$ & 1624 & $\delta_{\mathrm{s}} \mathrm{NH}_{3}$ \\
\hline $1536 \mathrm{~m}$ & $1519 \mathrm{vw}$ & & & & 1516 & $\mathrm{Ag}$ & $\delta_{\mathrm{s}} \mathrm{NH}_{3}(\mathrm{~N} 28)$ & 1596 & $\delta_{\mathrm{s}} \mathrm{NH}_{3}$ \\
\hline \multirow[t]{4}{*}{$1504 w$} & $1504 \mathrm{vw}$ & & & & 1493 & $\mathrm{Au}$ & wagCH $_{2}(\mathrm{C} 1)$ wagCH$_{2}(\mathrm{C} 13)$ & 1566 & $\rho \mathrm{N}-\mathrm{H}$ \\
\hline & $1470 w$ & & & & 1467 & $\mathrm{Ag}$ & $\delta \mathrm{CH}_{2}(\mathrm{C} 25) \delta \mathrm{CH}_{2}(\mathrm{C} 22)$ & 1539 & $\delta \mathrm{CH}_{2}$ \\
\hline & & & & & 1462 & $\mathrm{Au}$ & $\delta \mathrm{CH}_{2}(\mathrm{C} 19)$ & 1533 & $\delta \mathrm{CH}_{2}$ \\
\hline & & & & & 1458 & $\mathrm{Ag}$ & $\delta \mathrm{CH}_{2}(\mathrm{C} 40)$ & 1524 & $\delta \mathrm{CH}_{2}$ \\
\hline $1452 \mathrm{~s}$ & $1453 \mathrm{vw}$ & & & & 1453 & $\mathrm{Au}$ & $\delta \mathrm{CH}_{2}(\mathrm{C} 4)$ & 1518 & $\delta \mathrm{CH}_{2}$ \\
\hline \multirow[t]{4}{*}{$1452 \mathrm{~s}$} & $1453 \mathrm{vw}$ & & & & 1451 & $\mathrm{Ag}$ & $\delta \mathrm{CH}_{2}(\mathrm{C} 25)$ & 1516 & $\delta \mathrm{CH}_{2}$ \\
\hline & & & & & 1448 & $\mathrm{Au}$ & $\delta \mathrm{CH}_{2}(\mathrm{C} 13) \delta \mathrm{CH}_{2}(\mathrm{C} 16)$ & 1514 & $\delta \mathrm{CH}_{2}$ \\
\hline & & & & & 1446 & $\mathrm{Au}$ & $\delta \mathrm{CH}_{2}(\mathrm{C} 37)$ & 1510 & $\delta \mathrm{CH}_{2}$ \\
\hline & & & & & 1446 & $\mathrm{Ag}$ & $\delta \mathrm{CH}_{2}(\mathrm{C} 1)$ & 1506 & $\delta \mathrm{CH}_{2}$ \\
\hline
\end{tabular}




\begin{tabular}{|c|c|c|c|c|c|c|}
\hline & & 1441 & $\mathrm{Ag}$ & wagCH ${ }_{2}(\mathrm{C} 40)$ & 1499 & $\delta \mathrm{CH}_{2}$ \\
\hline & $1437 w$ & 1439 & $\mathrm{Au}$ & wagCH$_{2}(\mathrm{C} 19)$ & 1493 & $\delta \mathrm{CH}_{2}$ \\
\hline & $1437 w$ & 1437 & $\mathrm{Ag}$ & $\delta \mathrm{CH}_{2}(\mathrm{C} 22)$ & 1578 & wagCH${ }_{2}$ \\
\hline 1432sh & & 1431 & $\mathrm{Au}$ & $\delta \mathrm{CH}_{2}(\mathrm{C} 1) \delta \mathrm{CH}_{2}(\mathrm{C} 13)$ & 1574 & wagCH${ }_{2}$ \\
\hline \multirow[t]{7}{*}{1432 sh } & & 1430 & $\mathrm{Au}$ & $\delta \mathrm{CH}_{2}(\mathrm{C} 22)$ & 1532 & $\rho \mathrm{N}-\mathrm{H}$ \\
\hline & & 1424 & $\mathrm{Ag}$ & $\operatorname{wagCH}_{2}(\mathrm{C} 1)$ & 1568 & wagCH$H_{2}$ \\
\hline & & 1418 & $\mathrm{Ag}$ & $\rho \mathrm{N} 32-\mathrm{H} 33 \mathrm{wagCH}_{2}(\mathrm{C} 22)$ & 1550 & wagCH${ }_{2}$ \\
\hline & & 1408 & $\mathrm{Au}$ & $\rho^{\prime} \mathrm{N} 32-\mathrm{H} 33$ & 1538 & wagCH${ }_{2}$ \\
\hline & & 1399 & $\mathrm{Ag}$ & wagCH$_{2}(\mathrm{C} 16)$ & 1537 & wagCH${ }_{2}$ \\
\hline & & 1395 & $\mathrm{Au}$ & wagCH$_{2}(\mathrm{C} 37)$ & 1530 & wagCH${ }_{2}$ \\
\hline & & 1378 & $\mathrm{Au}$ & wagCH$_{2}(\mathrm{C} 13)$ & 1517 & wagCH${ }_{2}$ \\
\hline \multirow[t]{3}{*}{$1369 w$} & $1367 \mathrm{vw}$ & 1370 & $\mathrm{Ag}$ & wagCH ${ }_{2}(\mathrm{C} 34)$ & 1505 & wagCH${ }_{2}$ \\
\hline & & 1354 & $\mathrm{Au}$ & $\rho \mathrm{CH}_{2}(\mathrm{C} 19)$ & 1502 & wagCH$H_{2}$ \\
\hline & $1348 \mathrm{vw}$ & 1352 & $\mathrm{Au}$ & $\rho \mathrm{CH}_{2}(\mathrm{C} 40)$ & 1474 & wagCH${ }_{2}$ \\
\hline \multirow[t]{4}{*}{$1345 w$} & & 1340 & $\mathrm{Ag}$ & $\operatorname{wagCH}_{2}(\mathrm{C} 4)$ & 1429 & $\rho \mathrm{CH}_{2}$ \\
\hline & $1335 \mathrm{vw}$ & 1337 & $\mathrm{Ag}$ & $\rho \mathrm{CH}_{2}(\mathrm{C} 22)$ & 1426 & $\rho \mathrm{CH}_{2}$ \\
\hline & & 1324 & $\mathrm{Au}$ & wagCH $2(\mathrm{C} 25)$ & 1415 & $\rho \mathrm{CH}_{2}$ \\
\hline & $1315 \mathrm{vw}$ & 1320 & $\mathrm{Ag}$ & $\rho \mathrm{CH}_{2}(\mathrm{C} 4)$ & 1413 & $\rho \mathrm{CH}_{2}$ \\
\hline $1313 w$ & $1279 \mathrm{vw}$ & 1309 & $\mathrm{Au}$ & $\rho \mathrm{CH}_{2}(\mathrm{C} 25)$ & 1404 & $\rho \mathrm{CH}_{2}$ \\
\hline \multirow[t]{2}{*}{$1261 \mathrm{~m}$} & $1267 \mathrm{vw}$ & 1276 & $\mathrm{Ag}$ & $\rho \mathrm{CH}_{2}(\mathrm{C} 16)$ & 1398 & $\rho \mathrm{CH}_{2}$ \\
\hline & $1247 \mathrm{vw}$ & 1263 & $\mathrm{Ag}$ & $\rho \mathrm{CH}_{2}(\mathrm{C} 13)$ & 1378 & $\rho \mathrm{CH}_{2}$ \\
\hline \multirow[t]{2}{*}{$1237 w$} & $1234 \mathrm{vw}$ & 1238 & $\mathrm{Au}$ & $\rho \mathrm{CH}_{2}(\mathrm{C} 1)$ & 1369 & $\rho \mathrm{CH}_{2}$ \\
\hline & & 1202 & $\mathrm{Ag}$ & $\rho \mathrm{CH}_{2}(\mathrm{C} 16) \rho \mathrm{CH}_{2}(\mathrm{C} 13)$ & 1338 & $\rho \mathrm{CH}_{2}$ \\
\hline \multirow[t]{4}{*}{$1158 w$} & $1177 \mathrm{vw}$ & 1193 & $\mathrm{Au}$ & $\rho \mathrm{CH}_{2}(\mathrm{C} 37) \rho \mathrm{CH}_{2}(\mathrm{C} 34)$ & 1322 & $\rho \mathrm{CH}_{2}$ \\
\hline & $1139 \mathrm{vw}$ & 1130 & $\mathrm{Au}$ & $\rho \mathrm{NH}_{3}(\mathrm{~N} 7)$ & 1268 & $\rho \mathrm{NH}_{3}$ \\
\hline & $1123 \mathrm{vw}$ & 1123 & $\mathrm{Ag}$ & $\rho \mathrm{NH}_{3}(\mathrm{~N} 28)$ & 1250 & $\rho \mathrm{NH}_{3}$ \\
\hline & & 1100 & $\mathrm{Ag}$ & $\rho^{\prime} \mathrm{NH}_{3}(\mathrm{~N} 28) \tau w \mathrm{wH}_{2}(\mathrm{C} 25)$ & 1241 & $\rho \mathrm{CH}_{2}$ \\
\hline $1066 \mathrm{w}$ & $1066 \mathrm{vw}$ & 1097 & $\mathrm{Au}$ & $\rho^{\prime} \mathrm{NH}_{3}(\mathrm{~N} 7)$ & 1231 & $\rho \mathrm{NH}_{3}$ \\
\hline $1054 \mathrm{sh}$ & $1054 \mathrm{vw}$ & 1046 & $\mathrm{Ag}$ & $v \mathrm{~N} 11-\mathrm{C} 16 v \mathrm{C} 16-\mathrm{C} 34$ & 1214 & $\rho \mathrm{NH}_{3}$ \\
\hline \multirow[t]{3}{*}{$1030 w$} & $1028 \mathrm{vw}$ & 1035 & $\mathrm{Au}$ & $\beta R_{1}(\mathrm{~A} 1) v \mathrm{C} 13-\mathrm{C} 37$ & 1158 & $v \mathrm{~N}-\mathrm{CvC}-\mathrm{C}$ \\
\hline & & 1022 & $\mathrm{Ag}$ & $\beta \mathrm{R}_{1}(\mathrm{~A} 1) \vee \mathrm{C} 13-\mathrm{C} 37$ & 1180 & $\beta \mathrm{R}_{1}(\mathrm{~A} 1)$ \\
\hline & & 1010 & $\mathrm{Ag}$ & vC16-C34 & 1086 & $v \mathrm{C}-\mathrm{C}$ \\
\hline $999 m$ & & 996 & $\mathrm{Au}$ & $v \mathrm{C} 1-\mathrm{C} 4$ & 1081 & $v \mathrm{C}-\mathrm{C}$ \\
\hline $999 m$ & $986 \mathrm{vw}$ & 984 & $\mathrm{Au}$ & vC13-C37 & 1079 & $v \mathrm{C}-\mathrm{C}$ \\
\hline $990 \mathrm{sh}$ & $974 \mathrm{vw}$ & 978 & $\mathrm{Ag}$ & vC22-C25 & 1066 & $v \mathrm{C}-\mathrm{C}$ \\
\hline $947 \mathrm{~s}$ & $954 \mathrm{vw}$ & 952 & $\mathrm{Au}$ & $v \mathrm{C} 25-\mathrm{C} 40$ & 907 & $\tau \mathrm{wCH}_{2}$ \\
\hline \multirow[t]{3}{*}{$947 \mathrm{~s}$} & & 942 & $\mathrm{Ag}$ & $v \mathrm{~N} 7-\mathrm{C} 19 v \mathrm{C} 4-\mathrm{C} 19$ & 1049 & $v \mathrm{~N}-\mathrm{C} v \mathrm{C}-\mathrm{C}$ \\
\hline & & 937 & $\mathrm{Au}$ & $v \mathrm{~N} 28-\mathrm{C} 40$ & 1089 & $\rho \mathrm{NH}_{3}$ \\
\hline & $927 \mathrm{vw}$ & 924 & $\mathrm{Au}$ & $\rho^{\prime} \mathrm{NH}_{3}(\mathrm{~N} 28)$ & 1075 & $\rho \mathrm{NH}_{3}$ \\
\hline \multirow[t]{2}{*}{$915 \mathrm{w}$} & $911 \mathrm{vw}$ & 921 & $\mathrm{Ag}$ & $\tau \mathrm{wCH}_{2}(\mathrm{C} 34)$ & 988 & $v \mathrm{~N}-\mathrm{C} v \mathrm{C}-\mathrm{C}$ \\
\hline & $897 \mathrm{vw}$ & 900 & $\mathrm{Au}$ & $v \mathrm{~N} 32-\mathrm{C} 22 v \mathrm{~N} 28-\mathrm{C} 40$ & 981 & $v \mathrm{~N}-\mathrm{C} v \mathrm{C}-\mathrm{C}$ \\
\hline \multirow[t]{2}{*}{$875 w$} & $887 \mathrm{vw}$ & 891 & $\mathrm{Ag}$ & $v \mathrm{~N} 7-\mathrm{C} 19 v \mathrm{C} 4-\mathrm{C} 19$ & 977 & $v \mathrm{~N}-\mathrm{C} v \mathrm{C}-\mathrm{C}$ \\
\hline & $860 \mathrm{vw}$ & 866 & $\mathrm{Au}$ & vN7-C19 & 952 & $v \mathrm{~N}-\mathrm{C}$ \\
\hline $836 w$ & $840 \mathrm{vw}$ & 861 & $\mathrm{Ag}$ & $v \mathrm{~N} 11-\mathrm{C} 1$ & 931 & $v \mathrm{~N}-\mathrm{C}$ \\
\hline \multirow[t]{3}{*}{$808 w$} & $774 \mathrm{vs}$ & 843 & $\mathrm{Au}$ & $v \mathrm{~N} 32-\mathrm{C} 22 v \mathrm{~N} 32-\mathrm{C} 34$ & 788 & $\tau \mathrm{wCH}_{2}$ \\
\hline & $774 \mathrm{vs}$ & 789 & $\mathrm{Ag}$ & $\tau \mathrm{wCH}_{2}(\mathrm{C} 40)$ & 766 & $\tau \mathrm{wCH}_{2}$ \\
\hline & $767 \mathrm{sh}$ & 772 & $\mathrm{Au}$ & $\tau \mathrm{wCH}_{2}(\mathrm{C} 19) \tau \mathrm{wCH}_{2}(\mathrm{C} 1)$ & 886 & $v \mathrm{~N}-\mathrm{C}$ \\
\hline $756 w$ & $749 \mathrm{~s}$ & 745 & $\mathrm{Au}$ & $\tau \mathrm{wCH}_{2}(\mathrm{C} 16)$ & 743 & $\tau \mathrm{wCH}_{2}$ \\
\hline
\end{tabular}




\begin{tabular}{|c|c|c|c|c|c|c|c|c|c|}
\hline & $736 \mathrm{~m}$ & & & & 736 & $\mathrm{Ag}$ & $\begin{array}{l}\tau \mathrm{wCH}{ }_{2}(\mathrm{C} 13) \tau \mathrm{wCH}_{2}(\mathrm{C} 37) \\
v \mathrm{~N} 32-\mathrm{C} 37\end{array}$ & 724 & $\tau \mathrm{wCH}_{2}$ \\
\hline $708 w$ & $714 \mathrm{~m}$ & & & & 697 & $\mathrm{Au}$ & vN11-C16vN11-C13 & 705 & $\tau \mathrm{wCH} \mathrm{CH}_{2}$ \\
\hline $680 w$ & $675 w$ & & & & 684 & $\mathrm{Ag}$ & $\tau w \mathrm{wH}_{2}(\mathrm{C} 4)$ & 664 & $\tau w \mathrm{wH}_{2}$ \\
\hline $654 w$ & $668 w$ & & & & 684 & $\mathrm{Ag}$ & $\tau w \mathrm{wCH}_{2}(\mathrm{C} 25) \tau \mathrm{wCH} \mathrm{H}_{2}(\mathrm{C} 22)$ & 654 & $\tau \mathrm{wCH}_{2}$ \\
\hline \multirow[t]{2}{*}{$624 w$} & $627 \mathrm{w}$ & & & & 621 & $\mathrm{Au}$ & $\beta \mathrm{R}_{1}(\mathrm{~A} 1)$ & 783 & $\beta \mathrm{R}_{1}(\mathrm{~A} 1)$ \\
\hline & $601 w$ & & & & & & & 661 & $\beta \mathrm{R}_{2}(\mathrm{~A} 1)$ \\
\hline $596 w$ & $594 w$ & & & & & & & 450 & $\tau \mathrm{wCH}_{2}$ \\
\hline $562 w$ & $557 \mathrm{w}$ & & & & 531 & $\mathrm{Ag}$ & $\beta \mathrm{R}_{2}(\mathrm{~A} 1)$ & 552 & $\delta \mathrm{CNC}$ \\
\hline $523 w$ & $526 \mathrm{vw}$ & & & & 514 & $\mathrm{Au}$ & $\rho^{\prime} \mathrm{N} 11-\mathrm{H} 12$ & 533 & $\delta \mathrm{CNC}$ \\
\hline $493 w$ & $500 \mathrm{~m}$ & & & & 473 & $\mathrm{Ag}$ & $\delta \mathrm{C} 22 \mathrm{~N} 32 \mathrm{C} 34$ & 478 & $\delta \mathrm{CNC}$ \\
\hline $459 \mathrm{~s}$ & $482 \mathrm{w}$ & & & & 459 & $\mathrm{Ag}$ & $\delta \mathrm{C} 1 \mathrm{~N} 11 \mathrm{C} 13$ & 469 & $\delta \mathrm{CNC}$ \\
\hline \multirow[t]{37}{*}{$433 \mathrm{sh}$} & $474 \mathrm{~s}$ & & & & 435 & $\mathrm{Ag}$ & $\tau \mathrm{R}_{1}(\mathrm{~A} 1) \delta \mathrm{C} 1 \mathrm{~N} 11 \mathrm{C} 16$ & 430 & $\delta \mathrm{CCN}$ \\
\hline & $439 w$ & & & & 402 & $\mathrm{Au}$ & $\delta \mathrm{C} 25 \mathrm{C} 40 \mathrm{~N} 28$ & 367 & $\delta \mathrm{CNC}$ \\
\hline & $389 \mathrm{vw}$ & & & & 382 & $\mathrm{Ag}$ & $\rho \mathrm{N} 11-\mathrm{H} 12 \beta \mathrm{R}_{1}(\mathrm{~A} 1)$ & 291 & $\tau \mathrm{wNH}_{3}$ \\
\hline & $375 w$ & & & & 352 & $\mathrm{Au}$ & $\rho \mathrm{N} 11-\mathrm{H} 12 \delta \mathrm{C} 1 \mathrm{~N} 11 \mathrm{C} 16$ & 354 & $\delta \mathrm{CCC}$ \\
\hline & $365 w$ & & & & & & & 268 & $\tau \mathrm{wNH}_{3}$ \\
\hline & $276 v s$ & & & & & & & 290 & $v \mathrm{Bi}-\mathrm{Cl}$ \\
\hline & 276vs & & & & & & & 309 & $\delta \mathrm{CCC}$ \\
\hline & 276vs & & & & & & & 306 & $\delta \mathrm{CCC}$ \\
\hline & 276vs & & & & 293 & $\mathrm{Ag}$ & $\delta \mathrm{C} 22 \mathrm{~N} 32 \mathrm{C} 37$ & 299 & $\tau \mathrm{R}_{3}(\mathrm{~A} 1)$ \\
\hline & $276 v s$ & & & & 286 & $\mathrm{Au}$ & $\delta \mathrm{C} 1 \mathrm{C} 4 \mathrm{C} 19$ & 262 & $v \mathrm{Bi}-\mathrm{Cl}$ \\
\hline & $276 v s$ & & & & & & & 273 & $\tau \mathrm{R}_{2}(\mathrm{~A} 1)$ \\
\hline & $276 v s$ & & & & & & & 251 & $v \mathrm{Bi}-\mathrm{Cl}$ \\
\hline & $276 v s$ & & & & & & & 252 & $\delta \mathrm{CCC}$ \\
\hline & $239 \mathrm{sh}$ & & & & 239 & $\mathrm{Ag}$ & $\tau \mathrm{R}_{1}(\mathrm{~A} 1)$ & 244 & $\delta \mathrm{CCN}$ \\
\hline & $231 \mathrm{~s}$ & 230 & $\mathrm{~A}_{\mathrm{g}}$ & $v_{\mathrm{s}} \mathrm{Bi}_{2} \mathrm{Cl}_{10}(\mathrm{e}+\mathrm{a})$ & 231 & $\mathrm{Au}$ & $\delta \mathrm{C} 4 \mathrm{C} 19 \mathrm{~N} 7$ & 214 & $v \mathrm{Bi}-\mathrm{Cl}$ \\
\hline & $222 w$ & 222 & $\mathrm{~A}_{\mathrm{u}}$ & $v_{\mathrm{s}} \mathrm{BiCl}_{6}(\mathrm{e}+\mathrm{a})$ & & & & 210 & $v \mathrm{Bi}-\mathrm{Cl}$ \\
\hline & $209 \mathrm{sh}$ & 197 & $\mathrm{~A}_{\mathrm{u}}$ & $v_{\mathrm{a}} \mathrm{BiCl}_{4}(\mathrm{e})$ & 212 & $\mathrm{Au}$ & $\tau \mathrm{wNH}_{3}(\mathrm{~N} 28)$ & 203 & $v \mathrm{Bi}-\mathrm{Cl}$ \\
\hline & & & & & 211 & $\mathrm{Ag}$ & $\tau \mathrm{wNH}_{3}(\mathrm{~N} 7)$ & 168 & $\tau \mathrm{C}-\mathrm{C}$ \\
\hline & $191 \mathrm{sh}$ & 192 & $\mathrm{~A}_{\mathrm{g}}$ & $v_{\mathrm{a}} \mathrm{BiCl}_{6}(\mathrm{e})$ & 209 & $\mathrm{Au}$ & $\tau \mathrm{R}_{3}(\mathrm{~A} 1)$ & 184 & $v \mathrm{Bi}-\mathrm{Cl}$ \\
\hline & $191 \mathrm{sh}$ & & & & & & & 154 & $\tau \mathrm{C}-\mathrm{C}$ \\
\hline & $187 \mathrm{sh}$ & 188 & $\mathrm{~A}_{\mathrm{u}}$ & $v_{\mathrm{a}} \mathrm{Bi}_{2} \mathrm{Cl}_{4}(\mathrm{a})$ & 188 & $\mathrm{Ag}$ & $\delta \mathrm{C} 22 \mathrm{C} 25 \mathrm{C} 40$ & 174 & $v \mathrm{Bi}-\mathrm{Cl}$ \\
\hline & $176 \mathrm{sh}$ & 185 & $A_{g}$ & $v_{\mathrm{a}} \mathrm{Bi}_{2} \mathrm{Cl}_{10}(\mathrm{e}+\mathrm{a})$ & & & & 176 & $\delta \mathrm{CCC}$ \\
\hline & $176 \mathrm{sh}$ & 182 & $\mathrm{~A}_{\mathrm{u}}$ & $v_{\mathrm{a}} \mathrm{Bi}_{2} \mathrm{Cl}_{10}(\mathrm{e}+\mathrm{a})$ & & & & 138 & $\tau \mathrm{C}-\mathrm{C}$ \\
\hline & $165 w$ & & & & & & & 131 & $\tau \mathrm{C}-\mathrm{C}$ \\
\hline & $155 \mathrm{w}$ & 169 & $\mathrm{~A}_{\mathrm{g}}$ & $v_{\mathrm{a}} \mathrm{Bi}_{2} \mathrm{Cl}_{4}(\mathrm{a})$ & & & & 155 & $\delta \mathrm{Bi}_{2} \mathrm{Cl}_{4}$ \\
\hline & $155 \mathrm{w}$ & 160 & $\mathrm{~A}_{\mathrm{g}}$ & $\delta_{\mathrm{a}} \mathrm{Bi}_{2} \mathrm{Cl}_{4}(\mathrm{a})$ & & & & 149 & $\delta \mathrm{CCC}$ \\
\hline & $155 \mathrm{w}$ & & & & 146 & $\mathrm{Au}$ & $\tau \mathrm{R}_{2}(\mathrm{~A} 1)$ & 141 & $\tau \mathrm{R}_{2}(\mathrm{~A} 1)$ \\
\hline & $136 w$ & & & & & & & 126 & $v \mathrm{BiCl}_{4}$ \\
\hline & $136 w$ & & & & & & & 134 & wagBiCl $l_{4}$ \\
\hline & $131 w$ & 136 & $\mathrm{~A}_{\mathrm{u}}$ & $\delta_{\mathrm{a}} \mathrm{BiCl}_{6}(\mathrm{a}) \mathrm{v}_{\mathrm{a}} \mathrm{BiCl}_{4}(\mathrm{e})$ & & & & 129 & $\delta \mathrm{BiCl}_{6}$ \\
\hline & $131 w$ & 128 & $\mathrm{~A}_{\mathrm{u}}$ & $v_{\mathrm{a}} \mathrm{BiCl}_{4}(\mathrm{e})$ & & & & 125 & $\delta \mathrm{BiCl}_{6}$ \\
\hline & $121 \mathrm{sh}$ & 122 & $\mathrm{~A}_{\mathrm{u}}$ & $\mathrm{wagBiCl}_{4}(\mathrm{e}+\mathrm{a}) \delta_{\mathrm{a}} \mathrm{BiCl}_{6}$ & & & & 99 & $\tau \mathrm{C}-\mathrm{C}$ \\
\hline & $117 \mathrm{sh}$ & 119 & $\mathrm{~A}_{\mathrm{g}}$ & $\operatorname{wagBiCl}_{4}(\mathrm{e}+\mathrm{a})$ & 119 & $\mathrm{Ag}$ & $\tau \mathrm{C} 40-\mathrm{C} 25$ & 108 & $v \mathrm{Cl}-\mathrm{H}$ \\
\hline & $117 \mathrm{sh}$ & 117 & $\mathrm{~A}_{\mathrm{g}}$ & $\rho \mathrm{BiCl}_{4}(\mathrm{e})$ & & & & 86 & $\tau \mathrm{C}-\mathrm{C}$ \\
\hline & $114 \mathrm{~s}$ & 113 & $\mathrm{~A}_{\mathrm{u}}$ & $\rho \mathrm{BiCl}_{4}(\mathrm{e})$ & 114 & $\mathrm{Au}$ & $\tau \mathrm{C} 19-\mathrm{C} 4$ & 83 & $\tau \mathrm{C}-\mathrm{C}$ \\
\hline & $105 \mathrm{sh}$ & 110 & $\mathrm{~A}_{\mathrm{g}}$ & $\delta_{\mathrm{a}} \mathrm{BiCl}_{6}(\mathrm{e}+\mathrm{a})$ & 106 & $\mathrm{Ag}$ & $\delta \mathrm{C} 4 \mathrm{C} 1 \mathrm{~N} 11$ \&C25C22N32 & 102 & $\delta \mathrm{CCN}$ \\
\hline & 99sh & & & & & & & 96 & $\delta \mathrm{CCN}$ \\
\hline
\end{tabular}


99sh

$\begin{array}{lll}91 & \mathrm{~A}_{\mathrm{g}} & \delta_{\mathrm{a}} \mathrm{BiCl}_{6}(\mathrm{a}) \\ 90 & \mathrm{~A}_{\mathrm{u}} & \delta_{\mathrm{a}} \mathrm{BiCl}_{6}(\mathrm{e}) \\ 89 & \mathrm{~A}_{\mathrm{u}} & \mathrm{wagBiCl}_{4}(\mathrm{e}+\mathrm{a})\end{array}$

$75 \tau \mathrm{C}-\mathrm{C}$

(n)

89 $\mathrm{A}_{\mathrm{u}} \quad \mathrm{wagBiCl}_{4}(\mathrm{e}+\mathrm{a})$

$92 \mathrm{wagBiCl}_{4}$

$72 \tau \mathrm{C}-\mathrm{C}$

$85 \mathrm{wagBiCl}_{4}$

$66 \tau \mathrm{C}-\mathrm{C}$

\begin{tabular}{|c|c|c|c|c|c|c|c|}
\hline & & & & & & 63 & $\tau \mathrm{C}-\mathrm{C}$ \\
\hline 74 & $\mathrm{~A}_{\mathrm{u}}$ & $\delta_{\mathrm{a}} \mathrm{BiCl}_{6}(\mathrm{a}) \rho \mathrm{BiCl}_{4}(\mathrm{a})$ & 75 & $\mathrm{Ag}$ & $\tau \mathrm{C} 25-\mathrm{C} 22$ & 76 & $\delta_{\mathrm{a}} \mathrm{BiCl}_{6}$ \\
\hline 69 & $A_{g}$ & $\mathrm{\rho BiCl}_{4}(\mathrm{e}+\mathrm{a})$ & & & & 52 & $\tau \mathrm{C}-\mathrm{C}$ \\
\hline 68 & $\mathrm{~A}_{\mathrm{g}}$ & $\rho \mathrm{BiCl}_{4} \rho \mathrm{BiCl}_{4}$ & 64 & $\mathrm{Au}$ & $\tau \mathrm{C} 4-\mathrm{C} 1$ & 61 & $\rho \mathrm{BiCl}_{4}$ \\
\hline \multirow[t]{2}{*}{60} & $\mathrm{~A}_{\mathrm{g}}$ & $\delta_{\mathrm{a}} \mathrm{BiCl}_{4}(\mathrm{e}) \delta_{\mathrm{a}} \mathrm{BiCl}_{4}(\mathrm{e})$ & & & & 59 & $\delta_{\mathrm{a}} \mathrm{BiCl}_{4}$ \\
\hline & & & 50 & $\mathrm{Ag}$ & $\tau w C 22-\mathrm{N} 32$ & 54 & $\delta_{\mathrm{a}} \mathrm{BiCl}_{4}$ \\
\hline 47 & $\mathrm{~A}_{\mathrm{g}}$ & $v_{\mathrm{s}} \mathrm{BiCl}_{4}(\mathrm{e})$ & 47 & $\mathrm{Au}$ & $\tau \mathrm{R}_{2}(\mathrm{~A} 1)$ & 47 & $\tau \mathrm{Cl}-\mathrm{Bi}-\mathrm{Cl}-\mathrm{H}$ \\
\hline 44 & $\mathrm{~A}_{\mathrm{g}}$ & $\rho \mathrm{BiCl}_{4}(\mathrm{a})$ & & & & 45 & $\rho \mathrm{BiCl}_{4}$ \\
\hline 43 & $\mathrm{~A}_{\mathrm{g}}$ & $v_{\mathrm{a}} \mathrm{BiCl}_{4}(\mathrm{e})$ & & & & 34 & $\tau \mathrm{Cl}-\mathrm{Bi}-\mathrm{Cl}-\mathrm{H}$ \\
\hline 42 & & & & & & 29 & $\tau \mathrm{Cl}-\mathrm{Bi}-\mathrm{Cl}-\mathrm{H}$ \\
\hline & $\mathrm{A}_{\mathrm{g}}$ & $\delta_{\mathrm{a}} \mathrm{BiCl}_{4}(\mathrm{a})$ & 30 & $\mathrm{Au}$ & $\tau w C 1-\mathrm{N} 11$ & 29 & $\delta_{\mathrm{a}} \mathrm{BiCl}_{4}$ \\
\hline 32 & $\mathrm{~A}_{\mathrm{u}}$ & $\rho \mathrm{BiCl}_{4}(\mathrm{a}) \delta_{\mathrm{a}} \mathrm{BiCl}_{4}(\mathrm{e})$ & & & & 25 & $\delta_{\mathrm{a}} \mathrm{BiCl}_{4}$ \\
\hline
\end{tabular}

Abbreviations: $v$, stretching; $\beta$, deformation in the plane; $\gamma$, deformation out of plane; wag, wagging; $\tau$, torsion; $\beta_{\mathrm{R}}$, deformation ring $\tau_{\mathrm{R}}$, torsion ring; $\rho$, rocking; $\tau \mathrm{w}$, twisting; $\delta$, deformation; a, antisymmetric; s, symmetric; $\left(\mathrm{A}_{1}\right)$, Ring; (e), equatorial, (a), axial; Sym, symmetry; ${ }^{a}$ This work, 'brom scaled quantum mechanics force field, cFrom HF/SDD method. 
Table 8. Scaled internal force constants for $\left(\mathrm{C}_{10} \mathrm{H}_{28} \mathrm{~N}_{4}\right)^{4+}$ cation and $\left[\mathrm{Bi}_{2} \mathrm{Cl}_{10}\right]^{4-}$ anion in gas phase by using different theoretical methods.

\begin{tabular}{|c|c|c|c|}
\hline Force constants & $\frac{\text { B3LYP/6-31G*a }}{\left(\mathrm{C}_{10} \mathrm{H}_{28} \mathrm{~N}_{4}\right)^{4+}}$ & Force constants & $\frac{\mathrm{HF} / \mathrm{SDD}^{\mathrm{a}}}{\left[\mathrm{Bi}_{2} \mathrm{Cl}_{10}\right]^{4-}}$ \\
\hline$f(v N-H)$ & 5.83 & $f(v B i-C l)$ & $1.2-0.72$ \\
\hline$f\left(v \mathrm{NH}_{3}\right)$ & 5.92 & $f(\delta C l-B i-C l)$ & $0.8-0.2$ \\
\hline$f(v C-C)_{R}$ & 3.92 & & \\
\hline$f\left(v C H_{2}\right)$ & 4.69 & & \\
\hline$f\left(v C-N H_{3}\right)$ & 3.66 & & \\
\hline$f(\nu C-N)_{\text {Chain }}$ & 3.58 & & \\
\hline$f(\nu C-N)_{R}$ & 3.05 & & \\
\hline
\end{tabular}

